\title{
无机全固态电致变色材料与器件研究进展
}

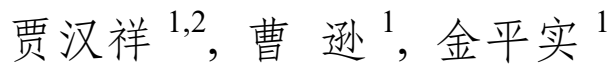

(1. 中国科学院 上海硅酸盐研究所, 高性能陶瓷和超微结构国家重点实验室, 上海 200050; 2. 中国科学院大学, 北京 100049)

摘 要: 智能场致变色材料是一类能在外场(电场、温度、光照、气氛)刺激下发生可逆光学变化的物质群。其中，电 致变色材料因其调节幅度大、响应速率快、着色效率高和循环稳定性好等特点，有望在智能窗、屏幕显示和多功 能储能器件等领域得到广泛应用。相较于半固态电致变色器件难于封装以及有机电致变色材料易于变性失效, 无机 全固态电致变色材料及其器件具有更好的综合应用性。本文聚焦典型无机全固态电致变色材料与器件, 综述了当前 电致变色器件各结构层的制备途径, 并对比了其优劣性, 详细介绍了主要的电致变色备选材料及其关键性能评价 指标, 并阐释了几种代表性电致变色器件的作用原理, 提出了使用兼具高透光率、低面电阻以及优异抗弯折性的透 明柔性电极替代传统的刚性祄底以实现多场响应器件的应用拓展。最后，从性能瓶颈、工艺难点及产业化机遇的角 度对无机全固态电致变色器件的应用前景进行了展望, 为电致变色产业化进程提供了借鉴。

关 键 词: 无机全固态; 电致变色器件; 材料选取; 结构设计; 应用前景; 综述

中图分类号: TQ174 文献标识码: A

\section{Advances in Inorganic All-solid-state Electrochromic Materials and Devices}

\author{
JIA Hanxiang ${ }^{1,2}$, CAO Xun $^{1}$, JIN Pingshi $^{1}$
}

(1. State Key Laboratory of High Performance Ceramics and Superfine Microstructure, Shanghai Institute of Ceramics, Chinese Academy of Sciences, Shanghai 200050, China; 2. Chinese Academy of Sciences, Beijing 100049, China)

\begin{abstract}
Chromogenic materials are capable of optical change reversibly in response to physical stimuli (e.g., electric field, temperature, illumination, and atmosphere). Among them, electrochromic materials are expected to be widely used in smart windows, screen displays, multi-functional energy storage devices and other fields due to their characteristics such as large adjustment range, fast response rate, high coloring efficiency and good cycle stability. However, compared with semi-solid-state electrochromic devices that are difficult to package and organic electrochromic materials that are prone to denaturation and failure, inorganic all-solid-state electrochromic materials and devices have better comprehensive application. This paper focuses on the typical inorganic all-solid-state electrochromic materials and devices, presents a brief review on the current preparation methods of each structure layer of electrochromic devices and compares its advantages and disadvantages, introduces in detail the main alternative electrochro-
\end{abstract}

收稿日期: 2019-06-24; 收到修改稿日期：2019-11-18

基金项目: 国家自然科学基金(51572284, 51972328, 51903244); 中国科学院青促会人才支持计划(2018288); 高性能陶瓷和 超微结构国家重点实验室青年基金(SKL201703); 上海市浦江人才项目(18PJD051); 安徽省重点研发计划 (1804a09020061)

National Natural Science Foundation of China (51572284, 51972328, 51903244); Youth Innovation Promotion Association, Chinese Academy of Sciences (2018288); Science Foundation for Youth Scholar of State Key Laboratory of High Performance Ceramics and Superfine Microstructures (SKL201703); Shanghai Pujiang Program (18PJD051);

Key Research and Development Plan of Anhui Province (1804a09020061)

作者简介: 贾汉祥(1993-), 男, 博士研究生. E-mail: jiahanxiang@student.sic.ac.cn

JIA Hanxiang(1993-), male, PhD candidate. E-mail: jiahanxiang@student.sic.ac.cn

通讯作者：曹 逊，研究员. E-mail: cxun@mail.sic.ac.cn

CAO Xun, professor. E-mail: cxun@mail.sic.ac.cn 
mic materials and its key performance evaluation index, and explains the principle of several representative electrochromic devices, proposes to use transparent flexible electrodes with both high light transmittance, low surface resistance and excellent bending fold to replace the traditional rigid substrate in order to realize multi-field responsible device application development. Finally, the application prospect of inorganic all-solid-state electrochromic devices is prospected from the perspective of performance bottleneck, process difficulty and industrialization opportunity, which provides reference for the industrialization process of electrochromic devices.

Key words: inorganic all-solid-state; electrochromic devices; material selection; structural design; application prospect; review

当今社会, 能源短缺和环境污染的形势日益严 峻，节能环保屡次被搬上国家和政府的工作议题， 驱动了该领域材料研发的热度 ${ }^{[1]}$ 。作为节能环保领 域的代表性材料, 场致变色材料是一类能在外场 (电场、温度、光照、气氛) 刺激下发生可逆光学变 化的物质统称, 主要分为电致变色 ${ }^{[2-3]}$ 、热致变色 ${ }^{[4-5]}$ 、 光致变色 ${ }^{[6-7]}$ 和气致变色 ${ }^{[8-9]}$ 材料等, 如图 1 所示。其 中, 电致变色材料能主动响应外加电场而产生稳 定、可逆的光学变化, 应用在建筑及汽车窗玻璃, 可 起到灵敏调控内部温度及光强的作用, 兼具节能及 舒适度的特点 ${ }^{[10]}$ 。

\section{1 电致变色材料}

电致变色材料在光热调控智能窗 ${ }^{[11]}$ 领域相较 于二氧化钒基热致变色材料具有独特优势, 通过微 弱的电信号即可灵敏地反馈出显著可逆的颜色变化,
这种主动可控的调节模式更易于满足实际应用所需, 并且在显示器 ${ }^{[15]}$ 、储能器件 ${ }^{[16]}$ 以及军用红外隐身等 领域也得到了广泛应用。近年来, 国内外众多课题 组均致力于电致变色的基础研究与应用拓展。中国 科学技术大学俞书宏团队 ${ }^{[17]}$ 通过朗格缪尔一布吉特 (L-B)技术开发的基于 $\mathrm{Ag} / \mathrm{W}_{18} \mathrm{O}_{49}$ 纳米线共组装体的 柔性电致变色器件，可实现不同图案的显示效果, 如图 2 所示，并且此结构易于大面积制备，颜色深 浅通过 $\mathrm{W}_{18} \mathrm{O}_{49}$ 纳米线的层数动态可调, 并具备一定 的柔性和机械稳定性，有望在显示面板领域得到应 用。而王金敏等 ${ }^{[18]}$ 则利用普鲁士蓝的电化学特性, 作为电致变色层实现了自供能电致变色-自充电透 明电池的双功能器件, 从图 3 可以看出, 器件裉色 对应放电过程，而显色对应充电过程。这一设计利 用了电致变色器件内部的电化学反应实现了自身的 充放电，在不引入外部电源的前提下进行有效调光， 且在放电过程中能驱动外接二极管发光。

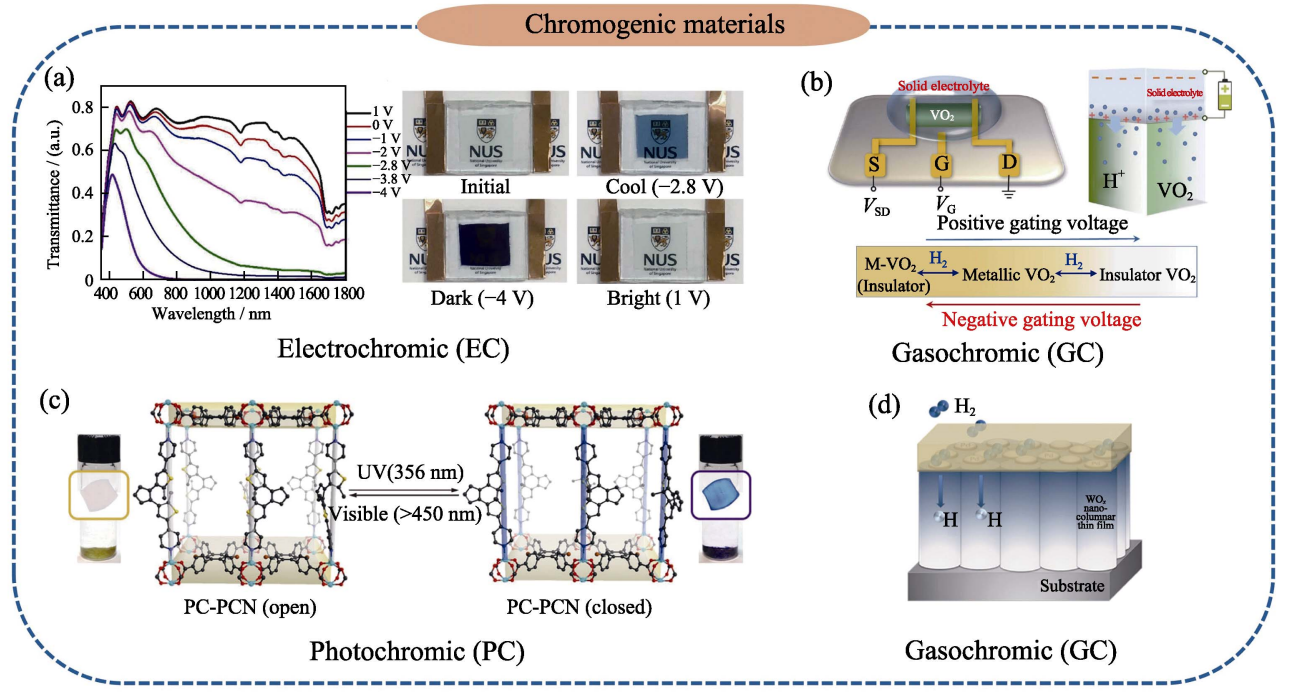

图 1 场致变色材料体系示例

Fig. 1 Schematic diagram of chromogenic system

(a) $\mathrm{Al}^{3+}$ based electrochromic device and its light modulation ${ }^{[11]}$; (b) Gate-controlled $\mathrm{VO}_{2}$ phase transition by tuning hydrogenating level for high-performance smart windows ${ }^{[12]}$; (c) Illustration of reversible photochromic reaction in PC-PCN (photochromic porous coordination network $)^{[13]}$; (d) Schematic description of the adsorption and diffusion of a $\mathrm{H}$ atom along $\mathrm{WO}_{x}$ based gasochromic thin film ${ }^{[14]}$ 

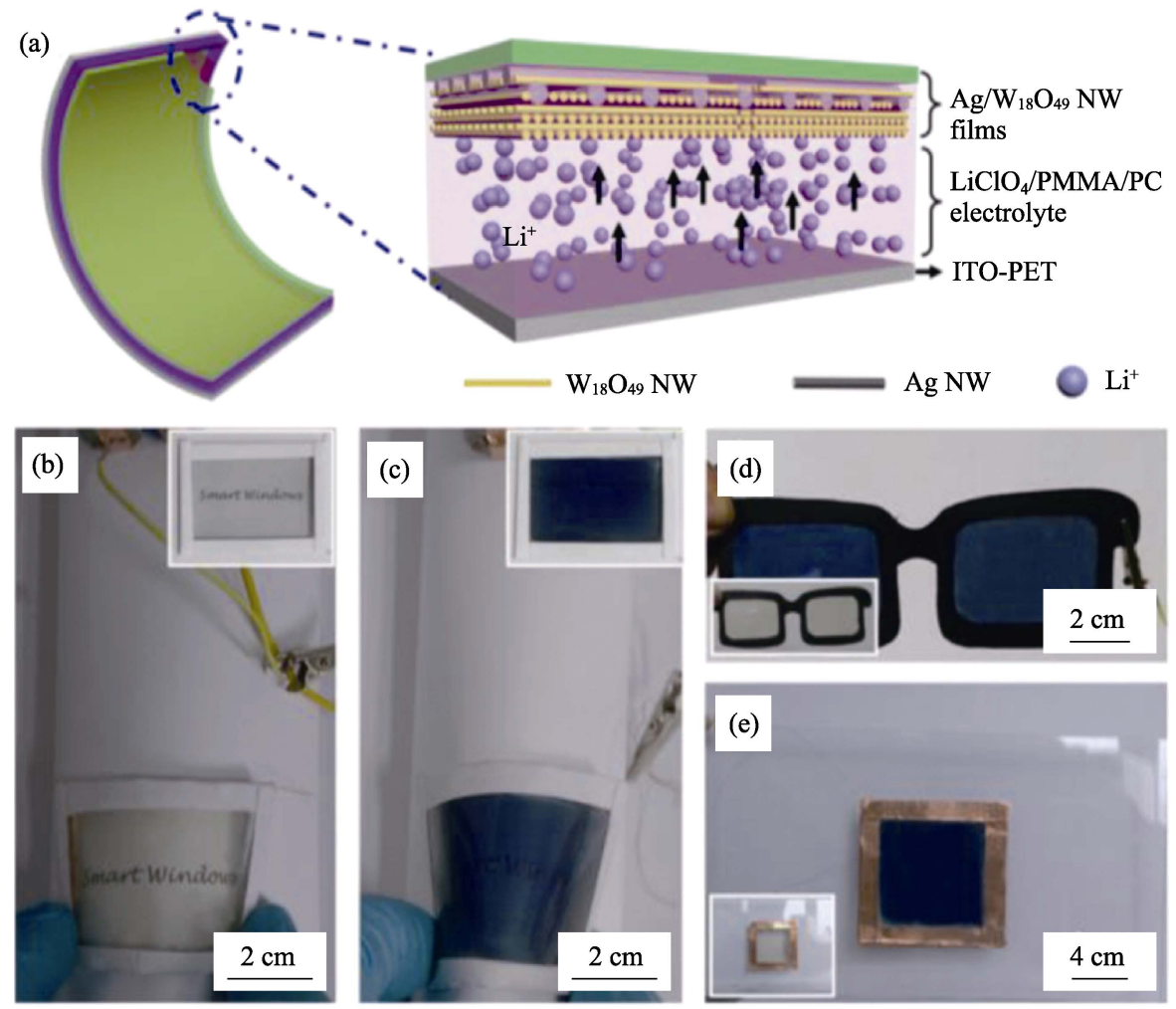

图 $2 \mathrm{Ag} / \mathrm{W}_{18} \mathrm{O}_{49}$ 纳米线共组装体柔性电致变色器件示意图(a)和照片 $(\mathrm{b} \sim \mathrm{e})^{[17]}$

Fig. 2 Schematic diagram (a) and photographs (b-e) of flexible electrochromic device of $\mathrm{Ag} / \mathrm{W}_{18} \mathrm{O}_{49}$ nanowire co-assemble $\mathrm{e}^{[17]}$

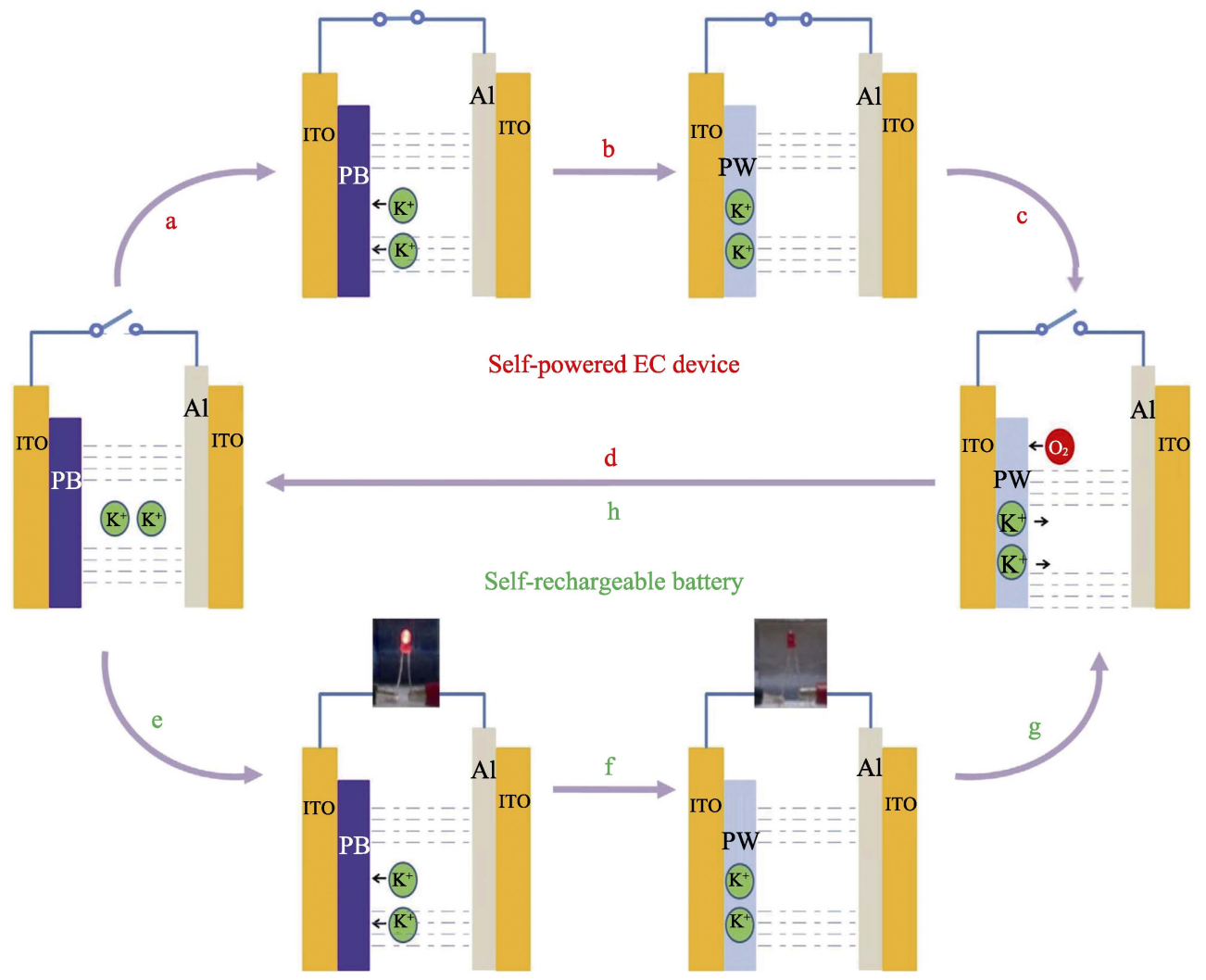

图 3 双功能器件作用机理示意图 ${ }^{[18]}$

Fig. 3 Schematic illustrations of functioning mechanisms for the bi-functional device ${ }^{[18]}$

设计多层结构的器件及不同类别的备选材料衍 生出了众多体系的电致变色器件。电致变色层除了
可选取过渡金属氧化物，常用的还包括有机聚合物。 而固态电解质除了陶瓷固态电解质，还有聚合物固 
态电解质。此外, 透明电极也有刚性 ${ }^{[19]}$ 和柔性 ${ }^{[20-21]}$ 之分, 因而由这些组分构成的多层电致变色器件种 类繁多。图 4 总结归纳了电致变色器件各功能层的 关键性能参数。

实验室小试阶段的电致变色器件, 往往采用聚 合物固态电解质或水系电解质, 以达到低成本、离 子易传导的目的, 但存在不便封装、稳定性较差的 劣势。对于实际应用的服役环境, 全固态体系的电 致变色器件往往更能符合要求。

近年来, 研究者们致力于电致变色器件各项性 能指标的优化, 通常采用高的调节幅度、短的响应 时间以及优良的循环稳定性; 特殊的结构、新型的 组分、层与层之间的界面调控等改性策略。

南京大学徐挺团队 ${ }^{[22]}$ 与美国马里兰大学的研 究者合作报道了一种基于等离子体共振吸收效应的 多重显色的电致变色器件, 采用了贵金属纳米栅格 的阵列结构, 中间填充有机电致变色材料聚苯胺 (PANI) 以增加电致变色层与电解质的接触面积, 同 时利用等离激元的共振吸收, 有效改善吸收波段的 迁移以呈现不同的颜色变化。此外, 新加坡国立大 学的 Lee 课题组 ${ }^{[11]}$ 以 $\mathrm{Al}^{3+}$ 为传输离子构造了具有快 速变色响应的双带调节电致变色器件, 具有优异稳 定性和可循环性, 在 2000 次着色/褪色循环后容量 仅损失 $5.5 \%$ 。

本文聚焦典型无机全固态电致变色材料与器件, 详细介绍代表性的电致变色备选材料及其器件设计 类型, 根据性能评价指标对电致变色的各层组分进行 篎选和比较, 在论述当前基础研究进展的同时, 并 从产业化的角度分析电致变色器件的性能瓶颈和工 艺难点, 为电致变色器件的应用前景提供参考。

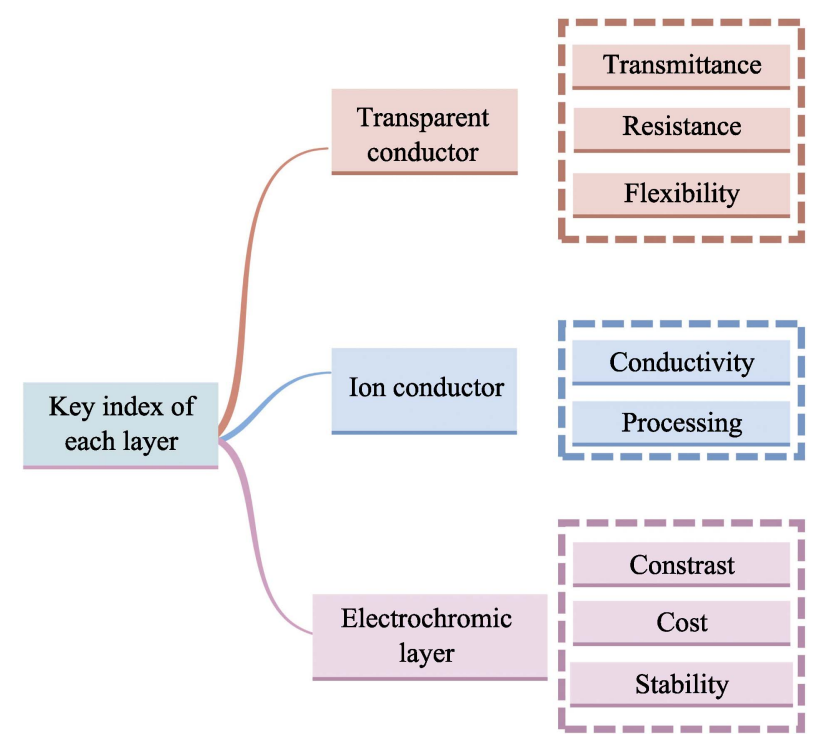

图 4 无机全固态电致变色器件各功能层及性能指标

Fig. 4 Performance index of the functional layers of inorganic all-solid-state electrochromic device

\section{2 电致变色器件的设计与制备}

\section{1 典型器件结构}

典型的电致变色器件为五层结构 ${ }^{[10]}$, 如图 5 所 示，即：器件项部和底部透明电极交叠层压中间的 三明治结构的离子存储层、电解质层、电致变色层。 其中, 电致变色层是器件调光的主导层, 在离子嵌 入、脱出时改变透光率, 分别对应于着色态和透明 态。离子存储层与电致变色层组成对电极, 可形成 颜色互补。而电解质在电致变色层与离子存储层之 间提供迁移离子。

\section{2 关键性能参数}

决定电致变色器件性能优异的评价参数主要有 五类，分别是：光学对比度、着色效率、响应时间、 循环稳定性和光学记忆 ${ }^{[3]}$, 如图 6 所示。

(1)光学对比度: 在一定波长范围内, 器件变色 前后对透光率的调节程度;

(2)着色效率 $\eta$ : 单位面积消耗的电量所引起的 吸光度变化, 与迁移离子的价态和半径有关;

(3)响应时间: 响应时间反映了电致变色材料显色/ 褪色的时间间隔，对于屏幕显示应用而言应尽可能快;

(4)循环稳定性: 电致变色器件在经历相当次数 的疲劳测试后其光学调节率的保持情况, 包括电化 学循环稳定性及机械循环稳定性;

(5)光学记忆: 当外场撤掉后, 电致变色材料恢 复初始光学态所需的时间, 一般以裉色时间长、着 色时间短为优。

\section{3 常用制备工艺}

对于无机电致变色器件的制备, 常见的主要有 磁控溅射法、溶胶一凝胶法、电化学沉积法、化学气 相沉积法、朗格缪尔-布吉特(L-B)技术等多种物理

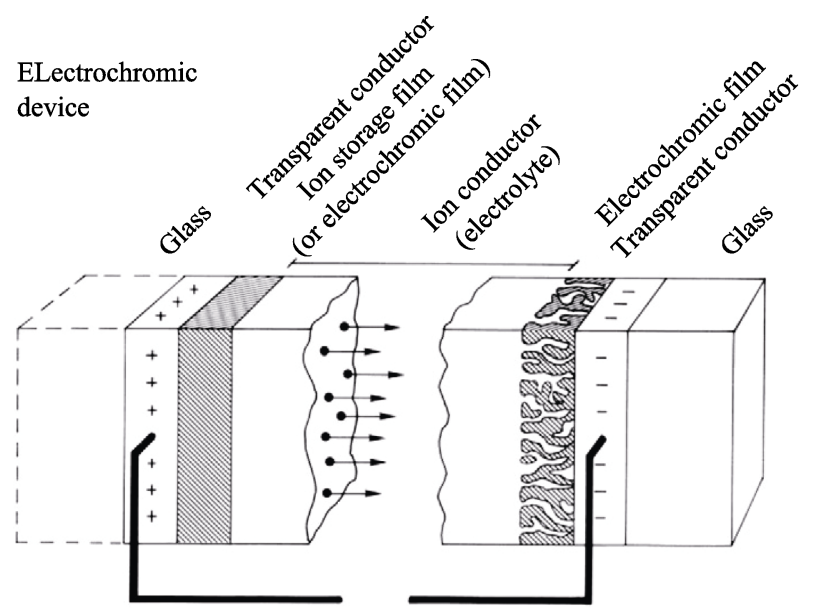

图 5 典型的电致变色器件结构示意图 ${ }^{[10]}$

Fig. 5 Schematic diagram of typical electrochromic device structure $^{[10]}$ 
化学方法(表 1)。实际制作过程中, 往往根据器件各 层的组分和物性选择适宜的制备方法。

\subsection{1 磁控浌射法}

磁控溅射法的优点在于各膜层均匀致密, 层与 层之间接触性良好, 是无机全固态电致变色器件的 主要制备方法, 然而采用该方法镀膜溅射效率较低, 对靶材、气氛、功率等参数有严格的要求, 难以开 展大规模生产制备。

Blackburn 等 ${ }^{[31]}$ 提出了一种利用磁控溅射技术制 备电致变色薄膜的界面改性策略。他们先采用化学 气相沉积法制备了石墨烯修饰的 FTO 祄底, 在此基 础上沉积生长 $\mathrm{NiO}$ 电致变色薄膜, 制备流程如图 7 所示。经过性能对比发现, 利用石墨烯修饰后的祄 底沉积生长的 $\mathrm{NiO}$ 薄膜, 在着色效率和透明度方面 表现更优。

\subsection{2 溶胶一凝胶法}

溶胶-凝胶法适于涂布凝胶态的聚合物以制备 透明电极(PEDOT:PSS, 金属纳米线)或电致变色层 (PANI, $\left.\mathrm{LiClO}_{4}-\mathrm{PC}\right)$, 其优势在于生产效率高且成本 低, 但制得的膜层质量一般。

Wolden 等 ${ }^{[32]}$ 采用溶胶-凝胶法制备了高性能的 介孔 $\mathrm{WO}_{3}$ 薄膜, 样品实物照片见图 8 。制得的溶胶 在水解 $12 \mathrm{~h}$ 后获得了最佳的电致变色性能。并且其 电致变色性能与退火条件密切相关, 改性后的薄膜

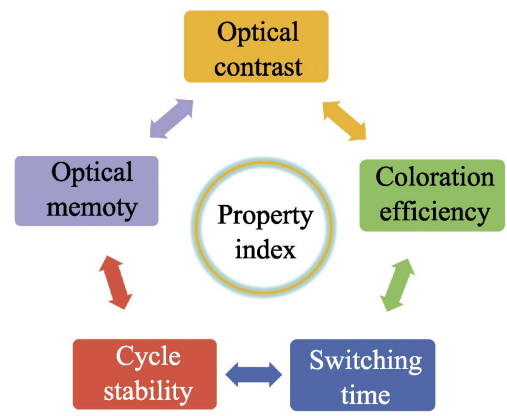

图 6 电致变色关键性能评价指标

Fig. 6 The key performance evaluation index of typical electrochromic device

表 1 主要的电致变色材料及制备方法

Table 1 Electrochromic materials and their deposition methods

\begin{tabular}{|c|c|c|}
\hline Category & EC Layer & Preparation method \\
\hline \multirow[t]{4}{*}{$\begin{array}{l}\text { Cathod } \\
\text { coloration }\end{array}$} & $\mathrm{WO}_{3}$ & $\begin{array}{l}\text { Magnetron sputtering }{ }^{[23]} \text {, vacuum } \\
\text { evaporation, Sol-Gel }\end{array}$ \\
\hline & $\mathrm{MoO}_{3}$ & $\begin{array}{l}\text { Magnetron sputtering } \\
\text { evaporation }^{[25]}\end{array}$ \\
\hline & $\mathrm{Nb}_{2} \mathrm{O}_{5}$ & Anodic oxidation $^{[26]}$ \\
\hline & $\mathrm{TiO}_{2}$ & Hydrothermal $^{[27]}$ \\
\hline \multirow{4}{*}{$\begin{array}{l}\text { Anode } \\
\text { coloring }\end{array}$} & $\mathrm{NiO}_{x}$ & Magnetron sputtering \\
\hline & $\mathrm{IrO}_{2}$ & Anodic oxidation ${ }^{[28]}$ \\
\hline & $\mathrm{CoO}_{2}$ & Hydrothermal $^{[29]}$ \\
\hline & Prussian blue & Electrochemical deposition ${ }^{[30]}$ \\
\hline
\end{tabular}

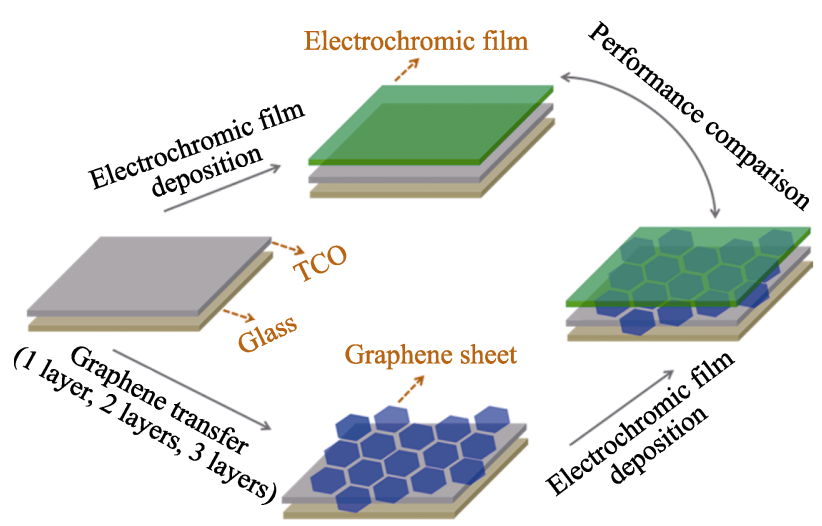

图 7 有无石墨烯界面层的电致变色电极的制备原理图 ${ }^{[31]}$

Fig. 7 Schematic illustration of the preparation for electrochromic electrodes with and without a graphene interface layer ${ }^{[31]}$
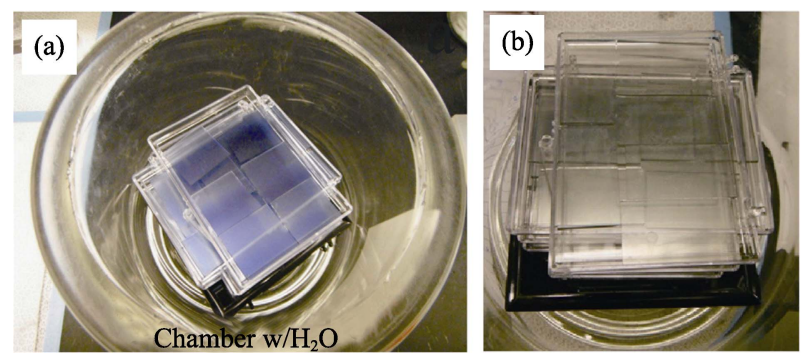

图 8 FTO 玻璃上凝胶薄膜图片 ${ }^{[32]}$

Fig. 8 Pictures of gel films on FTO glass ${ }^{[32]}$

(a) Immediately after spraying; (b) After $12 \mathrm{~h}$ of hydrolysis

显色效率提升，开关时间缩短。

\subsection{3 电化学沉积法}

电化学沉积法的制备参数可控, 沉积效率高, 适于利用模板制备特殊结构的膜层。浙江大学的涂 江平团队 ${ }^{[33]}$ 报道了一种基于自组装单层聚苯乙烯 (PS)球电沉积制备大面积周期性的碗状 $\mathrm{Co}_{3} \mathrm{O}_{4}$ 阵列 薄膜的简易方法。如图 9 所示, 去除 PS 球模板后, 便 得到周期性的 $\mathrm{Co}_{3} \mathrm{O}_{4}$ 薄膜网络, 分散孔径为 $1 \mathrm{pm}$ 。 经 $200{ }^{\circ} \mathrm{C}$ 退火的 $\mathrm{Co}_{3} \mathrm{O}_{4}$ 阵列薄膜具有良好的电致变 色性能。

\subsection{4 化学气相沉积法}

Mathur 等 ${ }^{[34]}$ 合成了新型单源前驱体 CVD 生长 $\mathrm{Nb}_{2} \mathrm{O}_{5}$ 薄膜及其电化学性能。不同温度下沉积的 $\mathrm{Nb}_{2} \mathrm{O}_{5}$ 薄膜表现出从低温四方相 $\left(\mathrm{TT}-\mathrm{Nb}_{2} \mathrm{O}_{5}, \mathrm{~T}-\mathrm{Nb}_{2} \mathrm{O}_{5}\right.$ ) 到高 温单斜相 $\left(\mathrm{H}-\mathrm{Nb}_{2} \mathrm{O}_{5}\right)$ 的系统相结构演化，如图 10 所示。

\subsection{5 朗格缪尔一布吉特 $(\mathbf{L}-\mathbf{B})$ 技术}

中国科学技术大学俞书宏团队 ${ }^{[17]}$ 开发了基于 纳米线共组装体的柔性电致变色器件。如图 11 所示, 首先通过 L-B 技术在柔性 PET 基底上将 Ag 纳米线 和 $\mathrm{W}_{18} \mathrm{O}_{49}$ 纳米线的悬浊液进行涂布组装，得到交叉 网格结构的 $\mathrm{Ag} / \mathrm{W}_{18} \mathrm{O}_{49}$ 纳米线共组装电致变色薄膜, 其透明度(58\% 86\%)和导电性(7 40 $\Omega / \square$ )均可通过 改变纳米线配比来进行调控。接着, 通过 L-B 技术 在 $\mathrm{Ag} / \mathrm{W}_{18} \mathrm{O}_{49}$ 纳米线网格结构上可以转移更多层数 


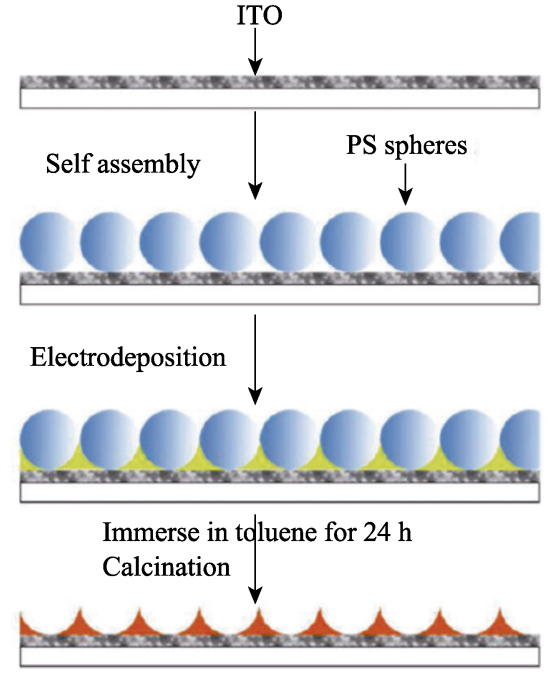

图 $9 \mathrm{Co}_{3} \mathrm{O}_{4}$ 宏观碗形阵列薄膜形成示意图 ${ }^{[33]}$

Fig. 9 Schematic illustration for the formation of $\mathrm{Co}_{3} \mathrm{O}_{4}$ macrobowl array films ${ }^{[33]}$
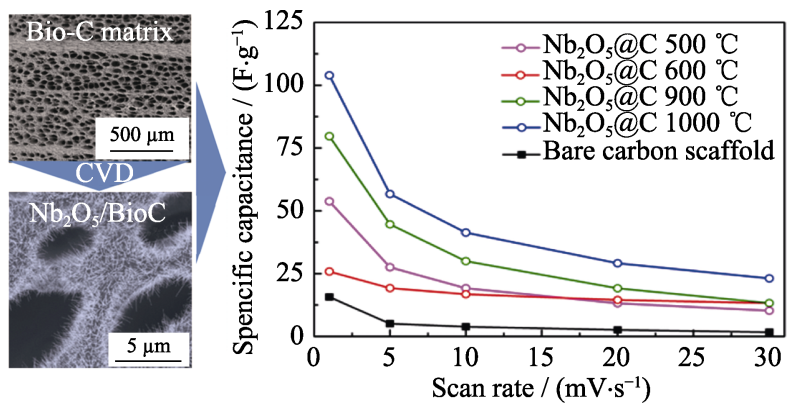

图 10 单源前驱体 $\mathrm{CVD}$ 生长 $\mathrm{Nb}_{2} \mathrm{O}_{5}$ 薄膜的控制合成 ${ }^{[34]}$

Fig. 10 Synthesis of $\mathrm{Nb}_{2} \mathrm{O}_{5}$ thin films grown by single source precursor $\mathrm{CVD}^{[34]}$

的 $\mathrm{W}_{18} \mathrm{O}_{49}$ 纳米线薄膜, 其电致变色性能随转移层数 动态可调。该电致变色膜可耐受 1000 次以上的弯折 疲劳测试, 且基本保持原有的导电率和电致变色性能。

\subsection{6 裂纹模板技术}

除了上述介绍的常用制备方法, 研究者们还设 计了一些新型的工艺用于器件结构优化。Guo 等 ${ }^{[35]}$ 提出了一种可控、大规模制备矩形银网的裂纹模板
技术, 用于制备无 ITO 柔性电致变色器件, 制备工 艺如图 12 所示。这种矩形银纳米网络具有优异的机 械稳定性和可控的光电性能(导电性 $2.0 \Omega / \square$, 透光 率 $91 \%$ )。在 $\mathrm{WO}_{3}$ 基电致变色器件中, $\mathrm{Ag}$ 矩形膜具 有超快的切换速率(脱色/着色时间 $=0.25 \mathrm{~s} / 0.18 \mathrm{~s}$ ), 因而可应用于面板显示。此外，该器件可组装成全 固态柔性电致变色器件 $(21 \mathrm{~cm} \times 13 \mathrm{~cm})$ 。

\section{3 透明电极}

\section{1 材料选取}

作为电致变色器件的重要组成部分, 透明电极 主要分为刚性和柔性两大类。刚性祄底常见的有掺 氟氧化锡(FTO)和掺铟氧化锡(ITO)。随着柔性电子 器件的兴起, 众多性能优异的柔性电极应运而生。 如图 13 所示, 通过在纳米 $\mathrm{Ag}$ 网格上复合一层 PEDOT:PSS, 可有效提升金属纳米线电极的导电性, 并改善着色均匀性 ${ }^{[36]}$ 。此复合电极兼具高的光透率 及优异的机械稳定性。此外, 2012 年国家纳米中心 魏志翔团队 ${ }^{[16]}$ 在有序 PANI(聚苯胺)纳米线阵列电 极的基础上，设计了一种集储能和电致变色功能于 一体的新型多功能电致变色储能智能窗, 该器件的 制备流程及工作原理如图 14 所示。

\section{2 评价指标}

为满足实际应用所需, 透明电极通常需兼具高 透光率、低面电阻以及良好的抗弯折性。柔性电极 除了抗弯折性的固有优势, 还需要在保证高透过率 的前提下面电阻尽可能低。

通常采用的透明电极主要有 $\mathrm{ITO}^{[37]}$ 、FTO ${ }^{[38]}$ 、 PEDOT:PSS ${ }^{[39]}$ 和碳纳米管等, 然而它们的面电阻可 达几十到几百欧姆, 有碍器件的变色切换速率 ${ }^{[36]}$ 。 此外, 脆性且成本高也是一大制约因素, 因此, 研 究者们致力于设计一种低电阻、高透光率的电极作
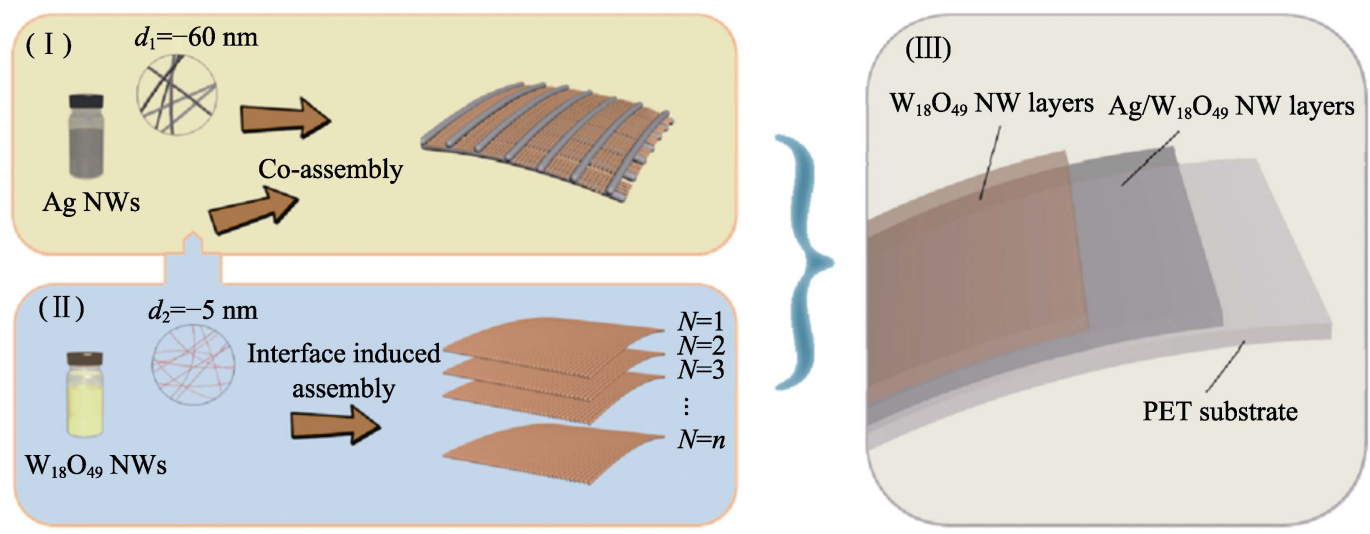

图 $11 \mathrm{~L}-\mathrm{B}$ 技术制备 $\mathrm{Ag} / \mathrm{W}_{18} \mathrm{O}_{49}$ 纳米线共组装体 ${ }^{[17]}$

Fig. $11 \mathrm{Ag} / \mathrm{W}_{18} \mathrm{O}_{49}$ nanowire co-assembles prepared by L-B technique ${ }^{[17]}$ 


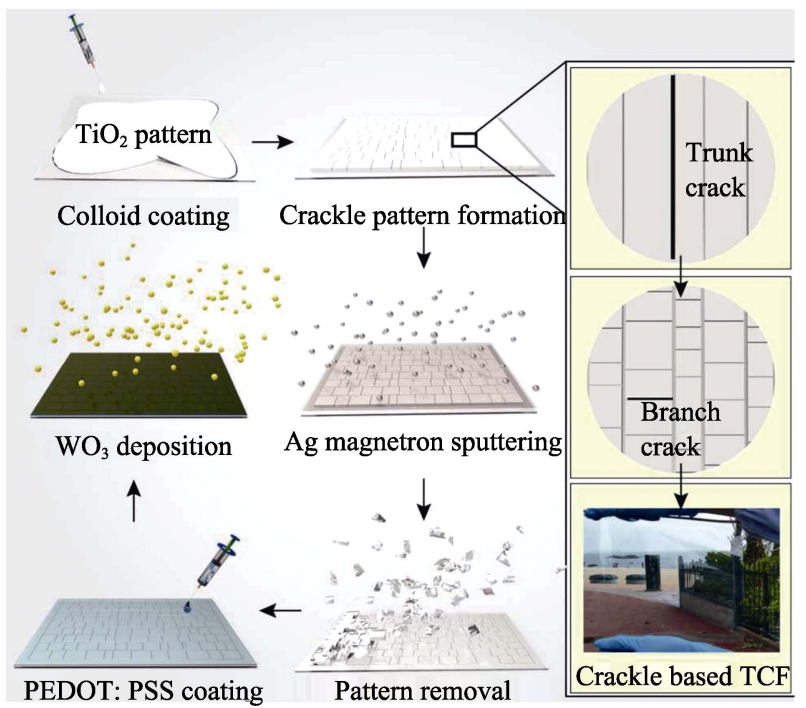

图 12 基于自形成裂纹模板技术的电致变色复合电极的制 造工艺示意图 ${ }^{[35]}$

Fig. 12 Schematic diagram of the fabrication process of the hybrid electrochromic electrode based on self-forming crackle pattern technology ${ }^{[35]}$
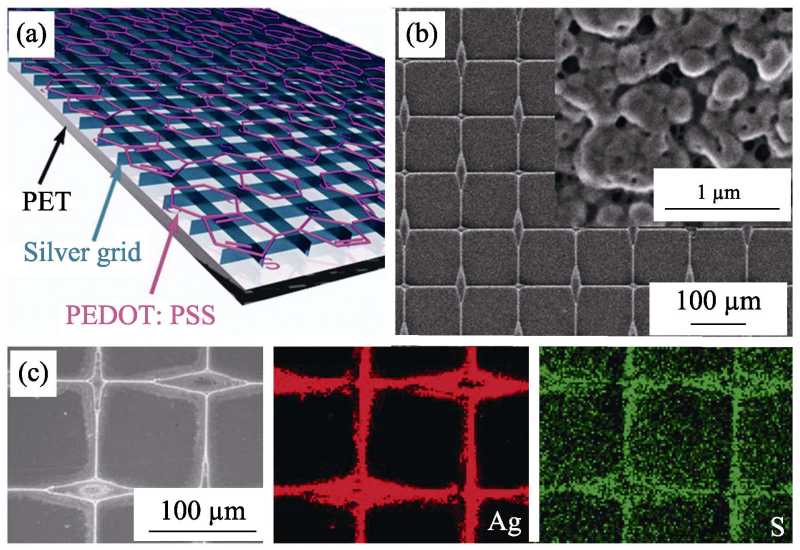

图 $13 \mathrm{Ag}$ 网格/PEDOT 复合柔性电极薄膜 ${ }^{[36]}$

Fig. 13 Ag grid/PEDOT hybrid flexible eletrode film ${ }^{[36]}$ (a) Schematic illustration of the structure of the silver grid/PEDOT:PSS hybrid film; (b) Low- and high-magnification SEM image of the hybrid film; (c) EDS mapping of the hybrid film, demonstrating the uniform distribution of PEDOT:PSS across the whole film

为其替代品。目前, 多种透明电极可作为 ITO 的低 成本替代品, 包括导电聚合物 ${ }^{[40-41]}$ 、碳纳米管 ${ }^{[42]}$ 、 石墨烯 ${ }^{[31,43]}$ 、金属纳米线 ${ }^{[17,21]}$ 和金属网格 ${ }^{[44]}$ 以及改 性的金属氧化物 ${ }^{[45]}$ 。

\section{3 器件性能}

为了研究上述基于纳米 $\mathrm{Ag}$ 网格/PEDOT:PSS 复 合电极的双功能器件的机械稳定性, 在曲率半径为 $20 \mathrm{~mm}$ 的条件下进行压缩和拉伸弯曲试验, 对器件 在着色/褪色过程中的透过率随弯曲循环次数的变 化进行实时测量。从图 15(a,b)可以看出, 在弯曲试 验达到 1200 次循环后, 其调光幅度仅降低了 $7.5 \%$ 左 右。此外, 在大约 800 次拉伸弯曲循环后, 调 (a)

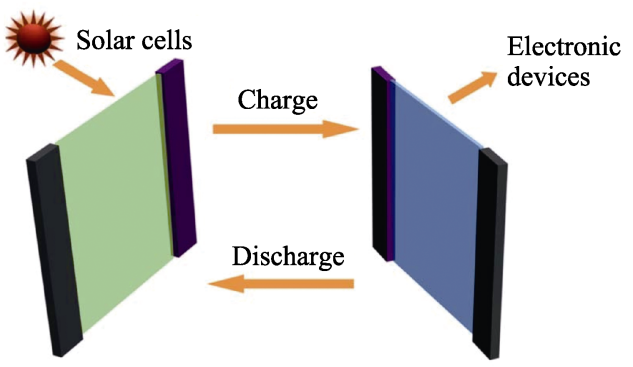

(b)

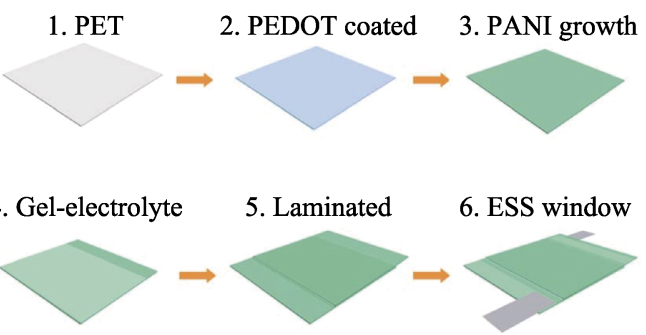

图 14 新型电致变色储能智能窗器件的系统方案(a)和设备 制备过程示意图(b) ${ }^{[16]}$

Fig. 14 Scheme of a new ESS window device system (a) and schematic for the device preparation process $(b)^{[16]}$

光幅度仅下降了约 $20 \%$, 如图 15(c,d) 所示。该双功 能器件具有优异的柔性和机械稳定性, 这一特性是 发展新兴柔性电子元器件必不可少的。

\section{4 固态电解质}

电解质对电致变色器件的性能有着重要影响, 其决定了电致变色器件切换过程中的离子/电子导 电率, 即电荷迁移率。对于全固态体系而言, 主要分 为两种类型: 陶瓷固态电解质和聚合物固态电解 质。此外, 迁移离子的价态对器件性能也有影响, 常 见的迁移离子包括一价的 $\mathrm{H}^{+[46-47]} 、 \mathrm{Li}^{+[48]} 、 \mathrm{Na}^{+[49]}$ 以 外, 还有二价的 $\mathrm{Mg}^{2+[50]}$ 和三价的 $\mathrm{Al}^{3+[11,51]}$ 。由于性 能稳定且便于封装, 在商用产品中, 固态电解质将 成为未来发展的主流趋势。

\section{1 陶瓷固态电解质}

常见的陶瓷固态电解质有 $\mathrm{LiTaO}_{3}$ 和 $\mathrm{LiNbO}_{3}$ 。 $\mathrm{LiTaO}_{3}$ 可通过 $\mathrm{Ta}_{2} \mathrm{O}_{5}$ 锂化制得, 具有良好的电化学 循环稳定性, 可利用磁控溅射法制备结晶态或非晶 态薄膜, 是全固态电致变色器件广泛使用的电解质 组分。

北京航空航天大学的刀训刚课题组 ${ }^{[52]}$ 报道了 一种基于 Glass $/ \mathrm{ITO} / \mathrm{WO}_{3} / \mathrm{LiTaO}_{3} / \mathrm{NiO} / \mathrm{ITO}$ 的单元器 件, 器件的微观结构如图 16 所示。其衰退机理在于 $\mathrm{NiO}$ 层对锂离子的捕获, ITO 顶电极出现“微孔”现象 以及 $\mathrm{LiTaO}_{3}$ 与 $\mathrm{WO}_{3}$ 层间脱附。这种锂捕获伴随氧 化镍形貌的演变, 可以解释该全无机电致变色器 件中电荷密度在变色转化过程中的衰退情况。 

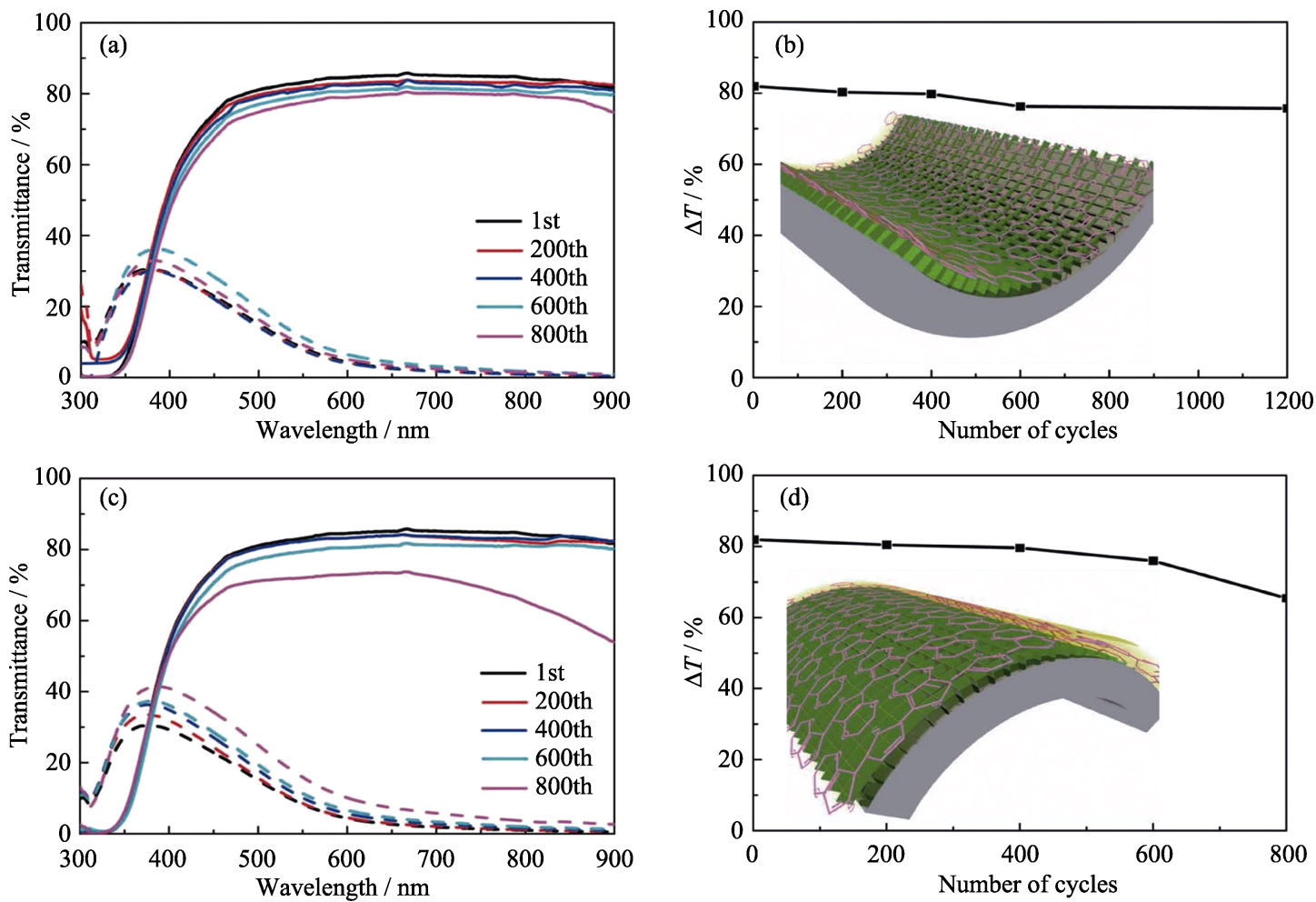

图 $15 \mathrm{Ag}$ 纳米网格/PEDOT:PSS 上的 $\mathrm{WO}_{3}$ 薄膜经过裉色和着色其透过率和光学调节幅度的变化 ${ }^{[36]}$

Fig. 15 Transmittance and optical modulation changes of the $\mathrm{WO}_{3}$ on the silver grid/PEDOT:PSS hybrid film in the bleached and colored state ${ }^{[36]}$

(a,b) Under repeated compressive bending; (c,d) Under repeated tensile bending. Curvature radius is $20 \mathrm{~mm}$

此外, 该团队 ${ }^{[53]}$ 还以 $\mathrm{LiNbO}_{3}$ 为电解质, 设计并 制备了 $\left(\mathrm{ITO} / \mathrm{NiO}_{x} / \mathrm{Ta}_{2} \mathrm{O}_{5} / \mathrm{LiNbO}_{3} / \mathrm{Ta}_{2} \mathrm{O}_{5} / \mathrm{WO}_{3} / \mathrm{ITO}\right)$ 的 七层无机全固态电致变色器件(图 17)。与典型的五 层无机电致变色器件相比, 其具有更好的光存储性

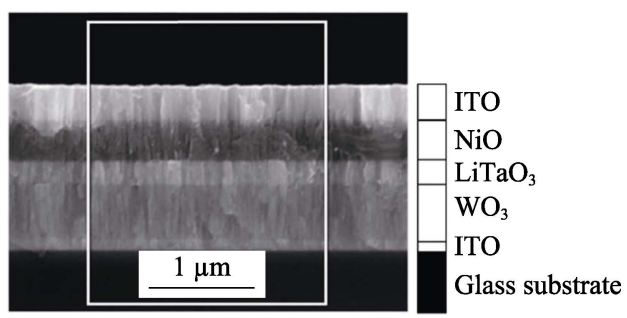

图 $16 \mathrm{Glass} / \mathrm{ITO} / \mathrm{WO}_{3} / \mathrm{LiTaO}_{3} / \mathrm{NiO} / \mathrm{ITO}$ 电致变色器件新鲜 断面的 SEM 照片 ${ }^{[52]}$

Fig. 16 SEM cross-section image of ECD-fresh: Glass/ITO/ $\mathrm{WO}_{3} / \mathrm{LiTaO}_{3} / \mathrm{NiO} / \mathrm{ITO}^{[52]}$
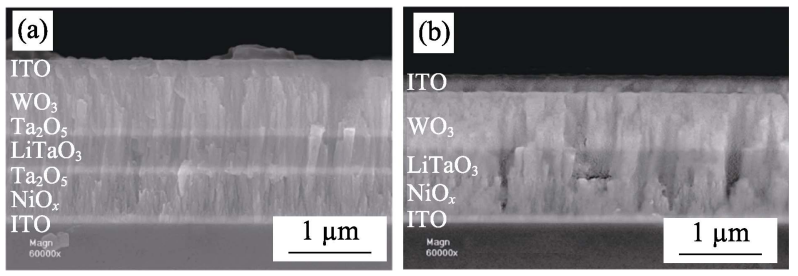

图 17 有无 $\mathrm{Ta}_{2} \mathrm{O}_{5}$ 层的两个电致变色器件的 SEM 截面照片 ${ }^{[53]}$

Fig. 17 SEM cross-sectional images (a-b) of ECD-1 and ECD-2 with and without the embedment of $\mathrm{Ta}_{2} \mathrm{O}_{5}$ layers ${ }^{[53]}$
能。 $\mathrm{Ta}_{2} \mathrm{O}_{5}$ 层的嵌入有效地增加了电解质层与电致变 色层之间的电子传输动力学能垒，从而限制了电子 泄漏量, 增大了电极间的电位阈值。因此, 器件可以 保持较高的开路电位和良好的光存储效果。该器件 在历经 10000 次循环后仍能以较慢的响应速度工作, 这与电致变色层中 $\mathrm{Li}^{+}$的俘获/脱出有关。

\section{2 聚合物固态电解质}

代表性的聚合物固态电解质为金属盐的聚合物 凝胶。其中, 多价的 $\mathrm{Al}^{3+}$ 电解质 ${ }^{[54]}$ 在电致变色器件 中的应用，不仅克服了传统电解质离子存在的一些 问题，还使得电致变色活性材料获得了更加优异的 性能, 推动了电致变色领域的进一步发展。与传统 的单价、小半径迁移离子相比, 多价离子有望得到 增强的显色对比度。

由于 $\mathrm{Al}^{3+}$ 与插层间存在强静电相互作用, 导致 多价离子插入层中的难度较大，因而以往这方面的 研究较少。苏州纳米所的赵志刚团队利用 $\mathrm{W}_{18} \mathrm{O}_{49}$ 为基材 (具有离子扩散距离短、表面多孔性好、与导 电祄底接触性好等优点), 三价 $\mathrm{Al}^{3+}$ 为插入离子, 使 $\mathrm{WO}_{3}$ 电致变色器件的性能相较传统电解质进一步 得到优化, 表现出快速开关、高对比度和高稳定性, 如图 18 所示。 $\mathrm{Al}^{3+}$ 的优势在于低成本和环保, 这一 发现为电致变色器件性能优化开辟了新的方向。 

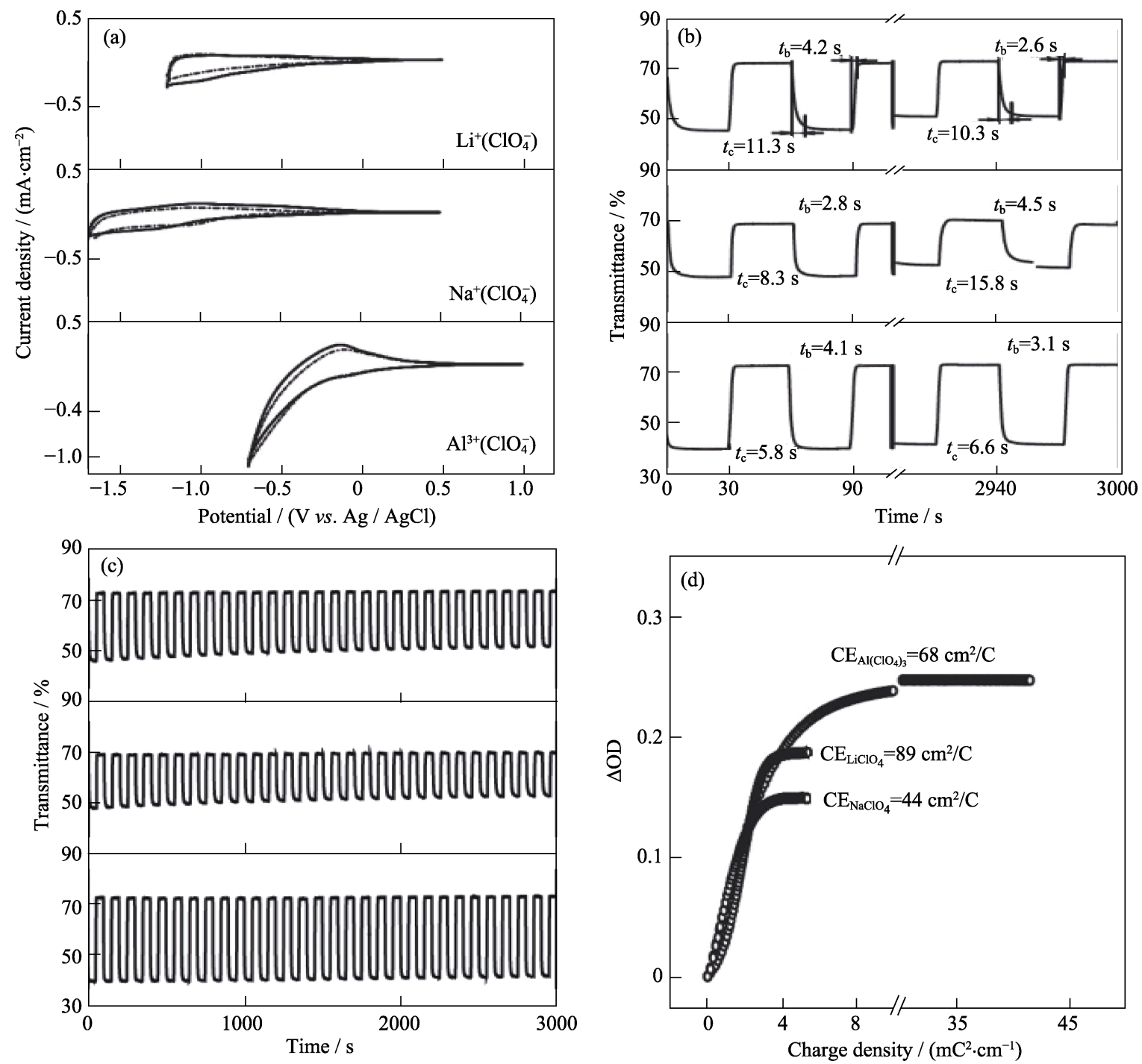

图 $18 \mathrm{~W}_{18} \mathrm{O}_{49}$ 纳米线在 $\mathrm{ClO}_{4}^{-}$作为抗衡离子的有机聚碳酸酯(PC)溶剂中, 以 $\mathrm{Li}^{+}$、

$\mathrm{Na}^{+}$或 $\mathrm{Al}^{3+}$ 进行电化学插入时的电致变色响应 ${ }^{[54]}$

Fig. 18 Electrochromic response of $\mathrm{W}_{18} \mathrm{O}_{49}$ nanowires under electrochemical insertion from one of the three different ions:

$\mathrm{Li}^{+}, \mathrm{Na}^{+}$, and $\mathrm{Al}^{3+}$ in organic polycarbonate (PC) solvent using $\mathrm{ClO}_{4}{ }^{-}$as counter ion under ambient conditions ${ }^{[54]}$

(a) $\mathrm{CV}$ curves (solid: the 1 st cycle, broken: the 30 th cycle) of the $\mathrm{W}_{18} \mathrm{O}_{49}$ nanowires film at a scan rate of $10 \mathrm{mV} \cdot \mathrm{s}^{-1}$ in $1.0 \mathrm{~mol} / \mathrm{L} \mathrm{PC}-\mathrm{Al}\left(\mathrm{ClO}_{4}\right)_{3}, \mathrm{PC}-\mathrm{LiClO}_{4}, \mathrm{PC}-\mathrm{NaClO}_{4}$; (b) In situ transmittance variation curves between colored and bleached state for

$\mathrm{W}_{18} \mathrm{O}_{49}$ nanowires film in $1.0 \mathrm{~mol} / \mathrm{L} \mathrm{PC}-\mathrm{Al}\left(\mathrm{ClO}_{4}\right)_{3}, \mathrm{PC}-\mathrm{LiClO}_{4}$, and $\mathrm{PC}-\mathrm{NaClO}_{4}$. Solid and broken lines are for the 1 st and 30th cycle, respectively; (c) Full plot of the in situ transmittance variation in the three non-aqueous solutions, a total of 30 cycles; (d) In situ OD variation as a function of charge density monitored at wavelength of $633 \mathrm{~nm}$ in $\left.\mathrm{PC}-\mathrm{LiClO}_{4}, \mathrm{PC}^{-\mathrm{NaClO}_{4}, \mathrm{PC}^{-} \mathrm{Al}_{(}(\mathrm{ClO}} 4\right)_{3}$

\section{5 电致变色层}

无机电致变色材料中研究最多应用最广的是过 渡金属氧化物和普鲁士蓝 $(\mathrm{PB})^{[55]}$ 。根据其变色特性 又可分为阴极着色材料(还原态时着色, 包括 $\mathrm{WO}_{3}$ 、 $\mathrm{MoO}_{3} 、 \mathrm{NbO}_{3} 、 \mathrm{TiO}_{2}$ 等)和阳极着色材料(氧化态时着 色，包括 $\mathrm{NiO}_{x} 、 \mathrm{IrO}_{x} 、 \mathrm{Co}_{2} \mathrm{O}_{3} 、 \mathrm{Rh}_{2} \mathrm{O}_{3} 、 \mathrm{MnO}_{2}$ 等)。 相较于有机电致变色材料的不稳定性, 无机电致变 色材料更适宜室外的服役条件。

典型的电致变色器件为类似电池型的五层构造 设计: 由两层透明导电祄底, 两层电活性材料(其中
至少有一层具有电致变色性能) 以及电解质所组成。 电解质所含有的迁移离子使相邻层的电致变色薄膜 发生着色和脱色的变化。在这一部分, 我们将主要 讨论其中具有代表性的阴极电致变色材料 $\left(\mathrm{WO}_{3}\right)$ 、 阳极电致变色材料 $(\mathrm{NiO})$ 以及普鲁士蓝 $(\mathrm{PB})$ 。

\section{1 阴极电致变色材料: $\mathrm{WO}_{3}$}

$\mathrm{WO}_{3}$ 是早期研究最广泛的无机电致变色材料, 现已实现产业化。通过对它施加电压，其颜色可在 白色与蓝色之间稳定可逆地转变。其电致变色反应 机理是电子和离子的双重注入和脱出过程。电致变 色反应中决定反应速率的离子脱嵌过程是受扩散控 
制的，因此切换速率与离子的扩散系数和基体的比 表面积紧密相关。

一般来说, 纳米结构的薄膜具有较大的比表面 积, 便于离子扩散, 从而引起更高的颜色对比度。另 外, 纳米结构材料可以避免离子输运时引起的体积 变化对主体材料的破坏。并且, 增加材料的比表面 积可以显著增加材料活性位点数。因此, 为了获得 快速的离子嵌入动力学和较好的循环稳定性, 纳米 结构设计独特的 $\mathrm{WO}_{3}$ 薄膜就显得非常重要 ${ }^{[56]}$ 。 $\mathrm{WO}_{3}$ 的电致变色性能在很大程度上取决于它的晶体结 构 $^{[57]}$ 。因此, 元素掺杂, 纳米结构设计和材料复合 改性可作为提高 $\mathrm{WO}_{3}$ 薄膜性能的有效策略。

非晶态 $\mathrm{WO}_{3}$ 薄膜作为阴极在调光型电致变色 器件中的应用引起了人们的广泛关注。然而, 这些 薄膜受制于离子诱捕引起的光调制和锂离子交换可 逆性的衰退。Wen 等 ${ }^{[58]}$ 证明了通常被认为是不可逆 的离子诱捕引起的退化, 可以通过恒流驱动的脱陷 而消除。如图 19 所示, $\mathrm{WO}_{3}$ 薄膜可以再生并恢复其 初始的高度可逆电致变色性能。在插入过程中, 当 $\mathrm{Li}_{x} \mathrm{WO}_{3}$ 中 $\mathrm{Li}^{+}$的比例超过 0.65 时, 会发生明显的离 子捕获。

\section{2 阳极电致变色材料: $\mathrm{NiO}$}

最常用的阳极电致变色材料是 $\mathrm{Ni}$ 和 Ir 的氧化
物，它们都可以在 $\mathrm{H}^{+}$脱嵌后从透明状态变为中性 色。使用 Ir 由于成本高, 储量有限 ${ }^{[59-60]}$ 而具有局限 性。相比之下, $\mathrm{NiO}$ 因其光学调节率高, 开关速度快, 循环稳定性优，记忆效果好和成本低而得到了广泛 的研究。此外, $\mathrm{NiO}$ 还可以作为离子存储层, 发挥其 颜色重叠的互补效应。

普遍认为, $\mathrm{NiO}$ 的电致变色性能是归因于电 子和阳离子的嵌入/脱嵌, 但是它强烈地依赖于离 子的扩散距离以及合适的比表面积, $\mathrm{NiO}$ 在商业应 用中仍有困难，因此有必要设计一种具有纳米结构 的 $\mathrm{NiO}$ 材料, 以获得快速插入动力学和增强耐 久性。

Lee 等 $^{[61]}$ 用一种简单、低成本的溶剂热法合成 了不同祄底上均匀的 $\mathrm{NiO}$ 纳米粒子, 表征结果如图 20 所示。电化学研究显示, 纳米 $\mathrm{NiO}$ 电极在充放电 过程中具有良好的反应可逆性和离子传输速度, 从 而获得了优异的电致变色性能，即使循环 5000 个周 期，其透过率也能保持在 $56.4 \%$ 左右。其优异的电 化学性能可能是由于形貌均匀且具有稳定的化学键 合，从而缩短了离子扩散距离，并大大促进了电荷 在接触界面和电极材料内的电化学转移过程。这项 工作展示了一种新型的智能超级电容电极, 其中的 储能阶段可以通过颜色变化进行可视化监控。
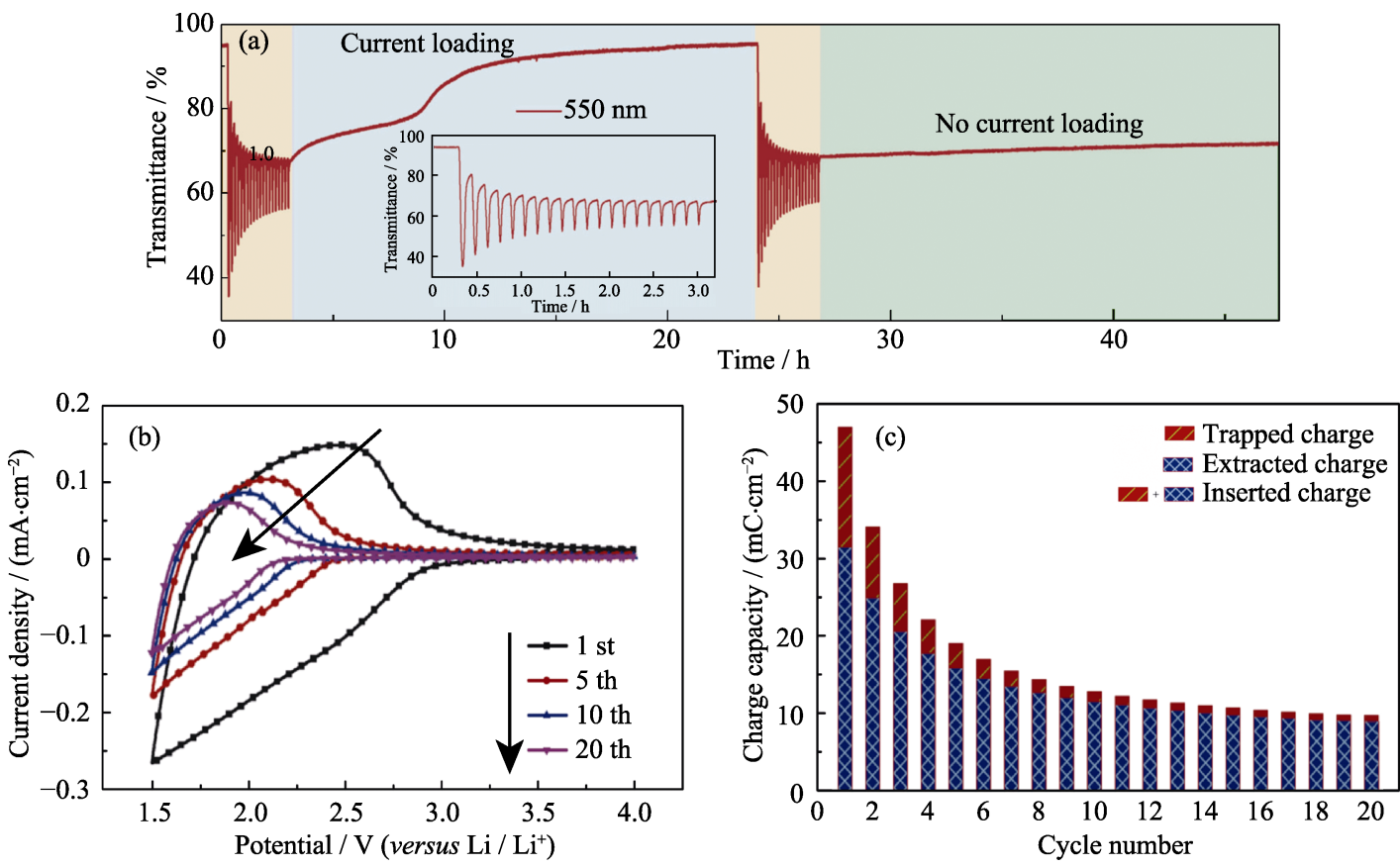

图 19 不同操作下 $\mathrm{WO}_{3}$ 薄膜的电致变色性能 ${ }^{[58]}$

Fig. 19 Electrochromic performance of $\mathrm{WO}_{3}$ films under various operations ${ }^{[58]}$ (a) Comparison of optical response at $550 \mathrm{~nm}$ and for 1.5-4.0 V with and without constant loading current, inset shows a magnified view of the transmittance during 20 initial cycles at $10 \mathrm{mV} \cdot \mathrm{s}^{-1}$; (b) CV data for different cycle numbers at $10 \mathrm{mV} \cdot \mathrm{s}^{-1}$; (c) Trapped and extracted charge densities $v$ s cycle number derived from $\mathrm{CV}$ data 

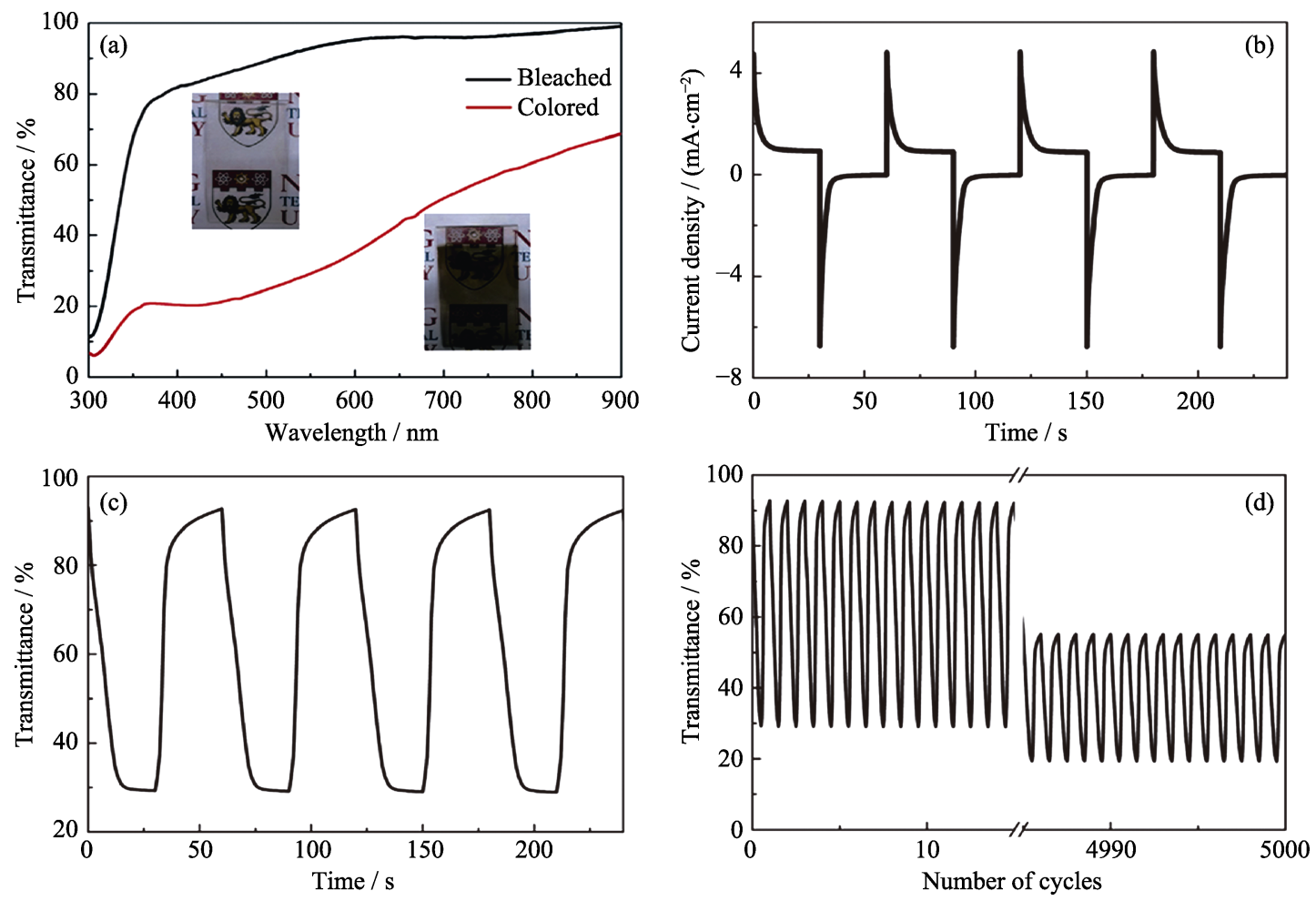

图 20 ITO 玻璃上有 $\mathrm{NiO}$ 籽晶层生长的 $\mathrm{NiO}$ 纳米薄膜的电致变色性能 ${ }^{[61]}$

Fig. 20 Electrochromic properties of NiO nanoparticles film with seed layer on ITO glass

(a) Transmittance spectra of the $\mathrm{NiO}$ nanoparticles film with seed layer on ITO glass in the bleached $(0.2 \mathrm{~V})$ and colored $(0.6 \mathrm{~V})$ states in the wavelength range of $300-900 \mathrm{~nm}$, with inset showing the digital photos of $\mathrm{NiO}$ film growing on

ITO glass with seed layer on bleached state and colored state; (b) Current response for NiO nanoparticles film at 0.2 and $0.6 \mathrm{~V}$ applications in $1 \mathrm{~mol} / \mathrm{L} \mathrm{KOH}$ for $30 \mathrm{~s}$ per step; (c) Corresponding in situ optical responses of $\mathrm{NiO}$ films for $30 \mathrm{~s}$ per step measured at $550 \mathrm{~nm}$; (d) Cycle performance of the $\mathrm{NiO}$ nanoparticles film measured in $1 \mathrm{~mol} / \mathrm{L} \mathrm{KOH}$ for $5000 \mathrm{cycles}^{[61]}$

以 $\mathrm{NiO}_{x}$ 作为对电极层, 由于褪色状态下的透明 度较差, 离子储存量不足, 限制了其在电致变色器 件(ECDs)中的应用。中国科学院上海硅酸盐所金平 实团队提出了一种基于梯度 $\mathrm{Li}^{+}$分布的 $\mathrm{Li}_{x} \mathrm{NiO}_{y}$ 全固 态电致变色器件(图 21), 该 ECDs 具有良好的电致 变色性能, 在 $550 \mathrm{~nm}$ 时的光学对比度为 $72.8 \%$, 着 色和褪色反应时间分别为 13 和 $3.5 \mathrm{~S}$ 。此外, 由于 $\mathrm{Li}$ 元素在对电极层的梯度分布, $\mathrm{Li}_{x} \mathrm{NiO}_{y}$ 层的顶部是 富锂的，在着色过程中可提供更多的 $\mathrm{Li}$ 离子。同时， $\mathrm{Li}_{x} \mathrm{NiO}_{y}$ 层的底部是贫锂的, 在褪色过程中可以容 纳更多的 $\mathrm{Li}$ 离子。该结构与传统的 $\mathrm{NiO}_{x}$ 基结构及 其它结构相比具有一定的优越性。

\section{3 普鲁士蓝(PB)}

普鲁士蓝 $(\mathrm{PB}), \mathrm{KFe}^{\mathrm{III}}\left[\mathrm{Fe}^{\mathrm{II}}(\mathrm{CN})_{6}\right]^{[62]}$ 是一种重要 的过渡金属六正氰酸盐, 在电化学、电致变色等方 面具有重要的研究价值。适宜的氧化还原反应位点 和优良的电致变色性能使其成为电致变色面板显示 的优异备选材料。目前, 已经有多种制备技术将 PB 组装或掺入所需的纳米结构中得到对应的电子器

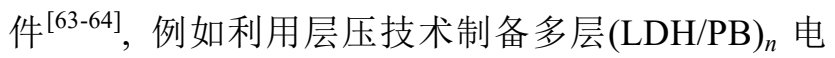
致变色膜, 工艺流程如图 22 所示。
王金敏课题组前期报道了集成化的自供电电致 变色器件与自充电电池的概念, 以普鲁士蓝 $(\mathrm{PB})$ 作 为电池正极、铝片作为牺牲负极, 制备得到的新型 器件实现了可逆的变色循环, 该器件在放电完成褪 色后，可通过自发的电化学反应实现自充电显色， 该过程仅耗时数小时。此外, 利用一步水热法生长 ${ }^{[65]}$ 的普鲁士绿薄膜相比电沉积法表现出更好的循环稳 定性。该普鲁士绿 $(\mathrm{PG})$ 基电致变色器件展示出可逆 的多阶变色。而且, 水热法制备的 PG 薄膜与 FTO 祄底结合更加牢固, 电致变色性能更加稳定 ${ }^{[66]}$ 。

\section{6 总结与展望}

本文从电致变色的原理及应用领域入手, 介绍 了无机全固态电致变色材料及其器件的发展现状。 从典型的器件结构出发, 列举了电致变色器件的关 键性能评价指标, 并对比了不同制备工艺的特点。

作为电致变色器件的重要组成部分, 透明电极 逐渐往柔性化方向发展以满足各类可穿戴电子器件 的应用需求。因而, 寻找合适的 ITO 替代物, 兼具 高透过率、低面电阻以及良好的机械稳定性就显得 

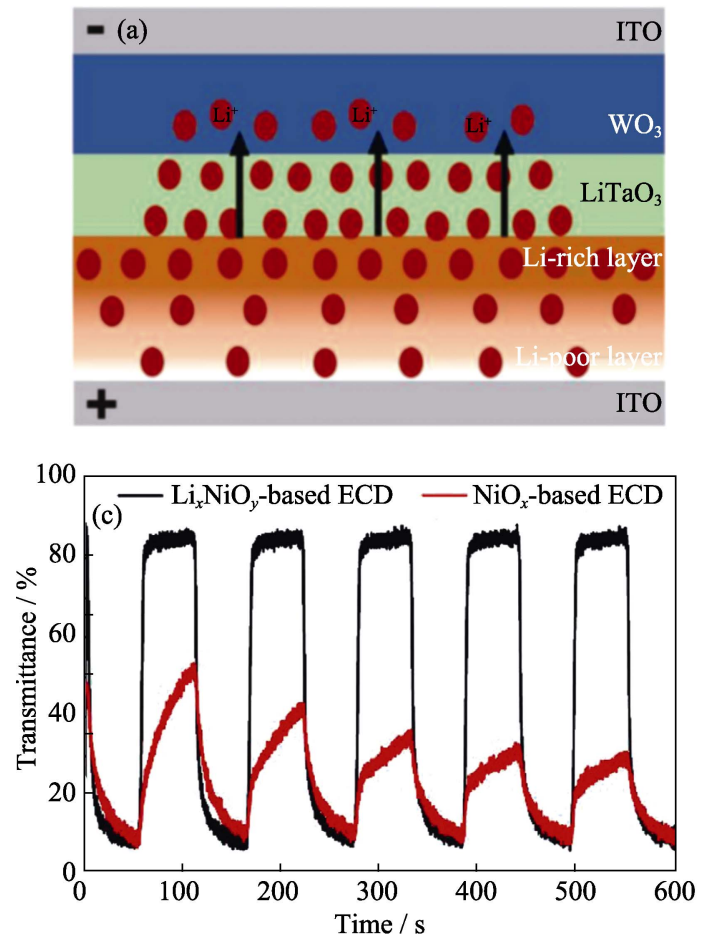
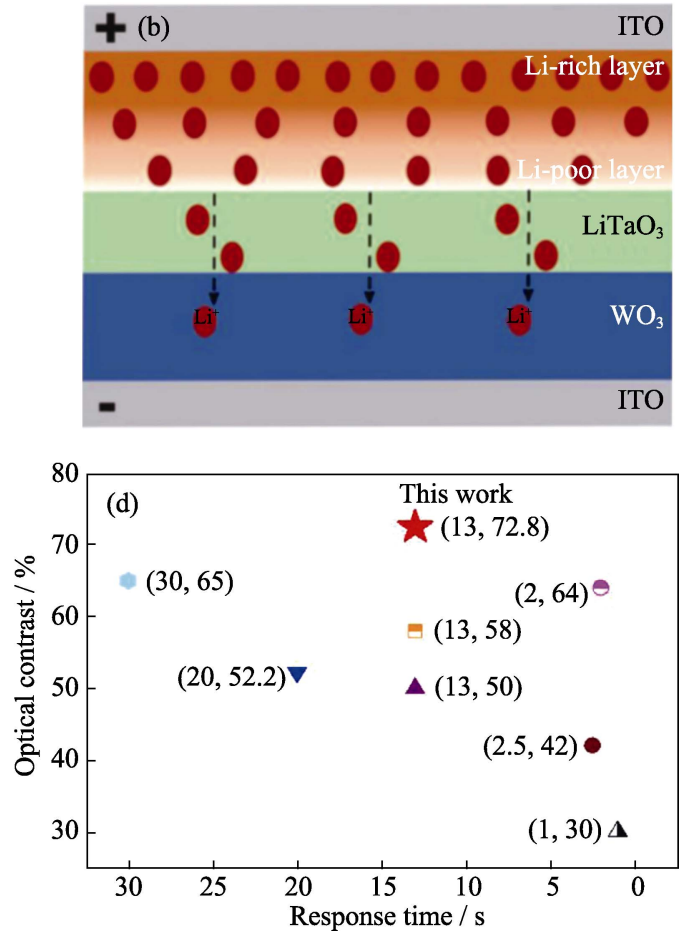

图 21 梯度 $\mathrm{Li}^{+}$分布的 $\mathrm{Li}_{x} \mathrm{NiO}_{y}$ 全固态电致变色器件及性能

Fig. $21 \mathrm{Li}_{x} \mathrm{NiO}_{y}$ all-solid-state ECDs based on gradient $\mathrm{Li}^{+}$distribution and its performance (a) Schematic diagram of Li ions transportation in the ECD-1 for the coloration process; (b) Schematic diagram of Li ions transportation in the ECD-2 for the coloration process; (c) Comparison of the transmittance variety at $670 \mathrm{~nm}$ of $\mathrm{Li}_{x} \mathrm{NiO}_{y}$-based ECD and $\mathrm{NiO}_{x}$-based ECD at $2.5 \mathrm{~V}$ bias; (d) Comparison of this work with recently reported all-solid-state ECDs

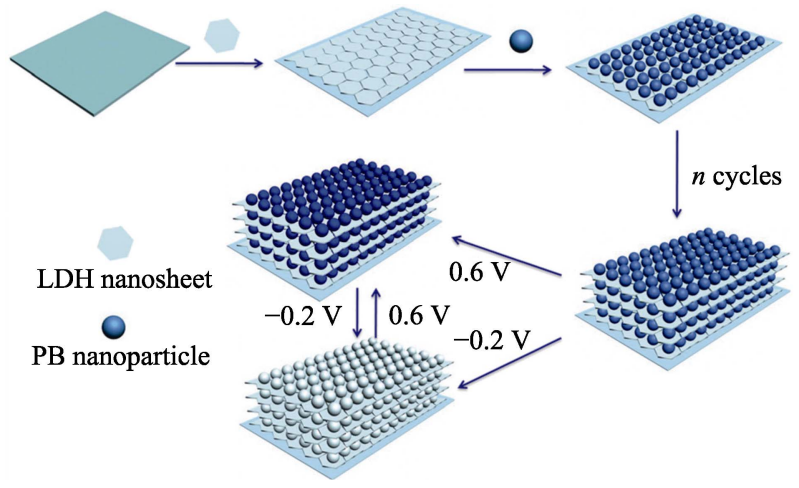

图 22 多层 $(\mathrm{LDH} / \mathrm{PB})_{n}$ 电致变色膜的 LBL 制造方法示意图 ${ }^{[63-64]}$ Fig. 22 Schematic representation for the LBL fabrication of the multilayered (LDH/PB) ${ }_{n}$ electrochromic film ${ }^{[63-64]}$

尤为关键。电解质决定了电致变色器件切换过程中 的电荷迁移率, 迁移离子的价态对器件性能也有影 响。固态电解质由于性能稳定且便于封装, 在商用 的电子器件中将成为未来发展的主流趋势。根据电 致变色材料的变色特性可分为阴极着色材料和阳极 着色材料, 相较于有机电致变色材料的不稳定性, 无机电致变色材料更适宜室外的服役条件。

综上所述, 通过优化备选材料和结构设计, 以 制备得到满足各项评价指标的无机全固态电致变色 器件, 有望推动电致变色器件的产业化进程。

\section{1 性能瓶颈及工艺难点}

推进电致变色产业化进程需要从生产工艺、效 率及成本上进行改进:

1) 电致变色层和对电极层须具有良好的纳米 孔隙率，而相应的制备参数条件难以摸索。

2) 透明电极必须具有低电阻率和高透过率。这 对基材选取和沉积工艺要求较为苛刻。

3) 器件尺寸扩大化的同时保持着色均匀性是 产业化的一大技术难题。

4) 电解质须兼具良好的离子导电率和尽可能 低的电子导电率, 从而保证器件切换速率及避免漏 电情况。

5) 持久的循环耐用性对智能窗户来说是一项 重要指标。

\section{2 产业化现状及前景}

目前，美国、德国和日本等国家的代表公司已 经实现电致变色玻璃的商用化，并应用于飞机舷 窗、大厦外窗幕墙和防眩目后视镜。而国内已完成 或正在中试的单位有威迪、上方、南玻等企业，国 内外在该领域的技术水平存在一定差距。

在国内，电致变色的量产化主要受制于设备昂 贵、工艺复杂以及自主知识产权的缺乏。由于电致 变色玻璃关键技术为国外垄断，国内集中攻关但尚 


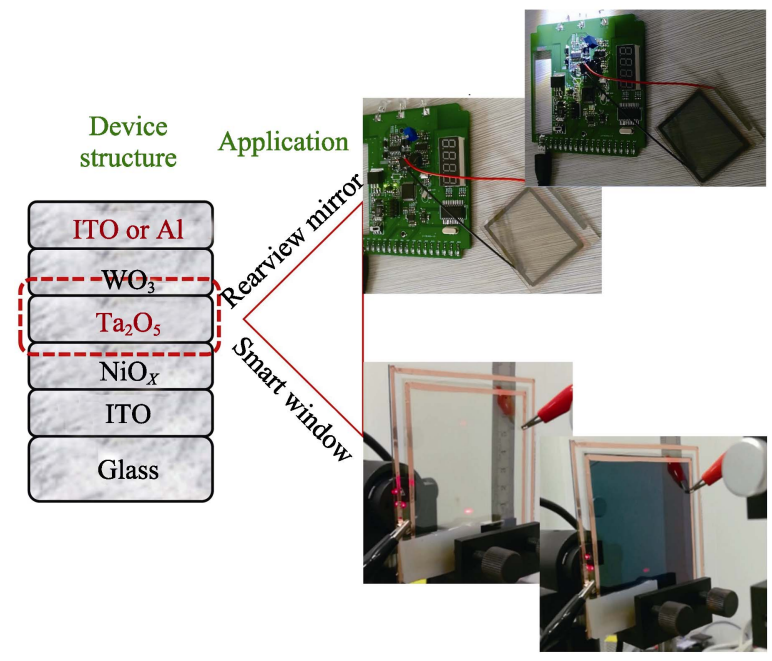

图 23 本团队研发的全固态电致变色器件

Fig. 23 All-solid-state electrochromic devices developed by our research group

未取得突破性进展, 本团队将重点研发体系中的新 材料、新结构、新工艺与设备的简化, 并注重建立 独立知识产权。

自上世纪 90 年代以来, 本团队致力于场致变色 体系材料的深入研究, 取得了一系列丰硕成果, 近 年来, 研发重点转向全固态电致变色玻璃的产业化, 相继研发出了性能优良的防眩目后视镜及智能变色 玻璃(图 23)。课题组充分借鉴锂离子电池领域的发 展趋势, 对钽酸锂以外的新介质层进行了广泛的探 索, 通过多层膜光学优化设计实现了器件调光性能 的最大化, 有望打通电致变色器件从中试到量产的 “最后一公里”。

\section{参考文献:}

[1] GRANQVIST C G. Recent progress in thermochromics and electrochromics: a brief survey. Thin Solid Films, 2016, 614: 90-96.

[2] GRANQVIST C G. Oxide-based chromogenic coatings and devices for energy efficient fenestration: brief survey and update on thermochromics and electrochromics. Journal of Vacuum Science \& Technology B, 2014, 32(6): 060801.

[3] THAKUR V K, DING G Q, MA J, et al. Hybrid materials and polymer electrolytes for electrochromic device applications. $A d$ vanced Materials, 2012, 24(30): 4071-4096.

[4] LIANG X, CHEN M, GUO S, et al. Dual-band modulation of visible and near-infrared light transmittance in an all-solution-processed hybrid micro-nano composite film. ACS Appl. Mater. Interfaces, 2017, 9(46): 40810-40819.

[5] LIANG X, CHEN M, WANG Q, et al. Active and passive modulation of solar light transmittance in a hybrid thermochromic soft-matter system for energy-saving smart window applications. Journal of Materials Chemistry C, 2018, 6(26): 7054-7062.

[6] FENG W, ZHANG T R, LIU Y, et al. Novel hybrid inorganicorganic film based on the tungstophosphate acid-polyacrylamide system: photochromic behavior and mechanism. Journal of Materials Research, 2011, 17(1): 133-136.

[7] LU N P, ZHANG P F, ZHANG Q H, et al. Electric-field control of tri-state phase transformation with a selective dual-ion switch. $\mathrm{Na}$ - ture, 2017, 546(7656): 124-128.

[8] FENG W, ZOU L P, GAO G H, et al. Gasochromic smart window: optical and thermal properties, energy simulation and feasibility analysis. Solar Energy Materials and Solar Cells, 2016, 144: 316-323.

[9] KALANUR S S, YOO I H, LEE Y A, et al. Green deposition of Pd nanoparticles on $\mathrm{WO}_{3}$ for optical, electronic and gasochromic hydrogen sensing applications. Sensors and Actuators B-Chemical, 2015, 221: 411-417.

[10] GRANQVIST C G. Electrochromics for smart windows: oxidebased thin films and devices. Thin Solid Films, 2014, 564: 1-38.

[11] ZHANG S L, CAO S, ZHANG T R, et al. $\mathrm{Al}^{3+}$ intercalation/ de-intercalation-enabled dual-band electrochromic smart windows with a high optical modulation, quick response and long cycle life. Energy \& Environmental Science, 2018, 11(10): 2884-2892.

[12] CHEN S, WANG Z W, REN H, et al. Gate-controlled $\mathrm{VO}_{2}$ phase transition for high-performance smart windows. Science Advances, 2019, 5(3): 8 .

[13] PARK J, FENG D, YUAN S, et al. Photochromic metal-organic frameworks: reversible control of singlet oxygen generation. Angew. Chem. Int. Ed. Engl., 2015, 54(2): 430-435.

[14] LEE Y A, KALANUR S S, SHIM G, et al. Highly sensitive gasochromic $\mathrm{H}_{2}$ sensing by nano-columnar $\mathrm{WO}_{3}$-Pd films with surface moisture. Sensors and Actuators B: Chemical, 2017, 238: 111-119.

[15] ALAMER F A, OTLEY M T, DING Y J, et al. Solid-state high-throughput screening for color tuning of electrochromic polymers. Advanced Materials, 2013, 25(43): 6256-6260.

[16] WANG K, WU H P, MENG Y N, et al. Integrated energy storage and electrochromic function in one flexible device: an energy storage smart window. Energy \& Environmental Science, 2012, 5(8): 8384-8389.

[17] WANG J L, LU Y R, LI H H, et al. Large area co-assembly of nanowires for flexible transparent smart windows. Journal of the American Chemical Society, 2017, 139(29): 9921-9926.

[18] WANG J M, ZHANG L, YU L, et al. A bi-functional device for self-powered electrochromic window and self-rechargeable transparent battery applications. Nat. Commun., 2014, 5: 4921.

[19] CAI G F, DARMAWAN P, CUI M Q, et al. Inkjet-printed all solid-state electrochromic devices based on $\mathrm{NiO} / \mathrm{WO}_{3}$ nanoparticle complementary electrodes. Nanoscale, 2016, 8(1): 348-357.

[20] BI Z J, LI X M, CHEN Y B, et al. Bi-functional flexible electrodes based on tungsten trioxide/zinc oxide nanocomposites for electrochromic and energy storage applications. Electrochimica Acta, 2017, 227: 61-68.

[21] SHEN L X, DU L H, TAN S Z, et al. Flexible electrochromic supercapacitor hybrid electrodes based on tungsten oxide films and silver nanowires. Chemical Communications, 2016, 52(37): 6296-6299.

[22] XU T, WALTER E C, AGRAWAL A, et al. High-contrast and fast electrochromic switching enabled by plasmonics. Nature Coтmunications, 2016, 7: 10479 .

[23] WANG M H, WEN J X, CHEN Y, et al. Nano-structured $\mathrm{WO}_{3}$ thin films deposited by glancing angle magnetron sputtering. Journal of Inorganic Materials, 2018, 33(12): 1303-1308.

[24] USHA N, SIVAKUMAR R, SANJEEVIRAJA C. Structural, optical and electrochromic properties of $\mathrm{Nb}_{2} \mathrm{O}_{5}: \mathrm{MoO}_{3}(95: 5,90: 10$, and $85: 15)$ thin films prepared by RF magnetron sputtering technique. Materials Letters, 2018, 229: 189-192.

[25] SIVAKUMAR R, SHANTHAKUMARI K, THAYUMANAVAN A, et al. Molybdenum oxide $\left(\mathrm{MoO}_{3}\right)$ thin film based electrochromic cell characterisation in $0.1 \mathrm{M} \mathrm{LiClO}_{4}$ center dot PC electrolyte. Surface Engineering, 2009, 25(7): 548-554.

[26] ROSENFELD D, SCHMID P E, SZELES S, et al. Electrical transport properties of thin-film metal-oxide-metal $\mathrm{Nb}_{2} \mathrm{O}_{5}$ oxygen sensors. Sensors and Actuators B-Chemical, 1996, 37(1/2): 83-89.

[27] CAI G F, TU J P, ZHOU D, et al. Multicolor electrochromic film based on $\mathrm{TiO}_{2} @$ polyaniline core/shell nanorod array. Journal of Physical Chemistry C, 2013, 117(31): 15967-15975.

[28] JUNG Y W, LEE J, TAK Y. Electrochromic mechanism of $\mathrm{IrO}_{2}$ prepared by pulsed anodic electrodeposition. Electrochemical and 
Solid State Letters, 2004, 7(2): H5-H8.

[29] SCHRADE M, FJELD H, FINSTAD T G, et al. Electronic transport properties of $\mathrm{Ca}_{2} \mathrm{CoO}_{3}$-delta (q) $\mathrm{CoO}_{2}$. Journal of Physical Chemistry C, 2014, 118(6): 2908-2918.

[30] DELONGCHAMP D M, HAMMOND P T. High-contrast electrochromism and controllable dissolution of assembled Prussian blue/polymer nanocomposites. Advanced Functional Materials, 2004, 14(3): 224-232.

[31] LIN F, BULT J B, NANAYAKKARA S, et al. Graphene as an efficient interfacial layer for electrochromic devices. ACS Applied Materials \& Interfaces, 2015, 7(21): 11330-11336.

[32] LI C P, LIN F, RICHARDS R M, et al. The influence of Sol-Gel processing on the electrochromic properties of mesoporous $\mathrm{WO}_{3}$ films produced by ultrasonic spray deposition. Solar Energy Materials and Solar Cells, 2014, 121: 163-170.

[33] XIA X H, TU J P, ZHANG J, et al. Cobalt oxide ordered bowl-like array films prepared by electrodeposition through monolayer polystyrene sphere template and electrochromic properties. ACS Applied Materials \& Interfaces, 2010, 2(1): 186-192.

[34] FIZ R, APPEL L, GUTIERREZ-PARDO A, et al. Electrochemical energy storage applications of CVD grown niobium oxide thin films. ACS Applied Materials \& Interfaces, 2016, 8(33): 21423-21430.

[35] XU Z J, LI W F, HUANG J N, et al. Controllable and large-scale fabrication of flexible ITO-free electrochromic devices by crackle pattern technology. Journal of Materials Chemistry A, 2018, 6(40): 19584-19589.

[36] CAI G F, DARMAWAN P, CUI M Q, et al. Highly stable transparent conductive silver grid/pedot:pss electrodes for integrated bifunctional flexible electrochromic supercapacitors. Advanced Energy Materials, 2016, 6(4): 1501882.

[37] YE T, XIANG Y, JI H, et al. Electrodeposition-based electrochromic devices with reversible three-state optical transformation by using titanium dioxide nanoparticle modified FTO electrode. RSC Advances, 2016, 6(37): 30769-30775.

[38] ZHOU Y L, DIAO X G, DONG G B, et al. Enhanced transmittance modulation of ITO $/ \mathrm{NiO}_{x} / \mathrm{ZrO}_{2}: \mathrm{H} / \mathrm{WO}_{3} / \mathrm{ITO}$ electrochromic devices. Ionics, 2016, 22(1): 25-32.

[39] ZHANG S M, CHEN Y H, LIU H, et al. Room-temperatureformed PEDOT:PSS hydrogels enable injectable, soft, and healable organic bioelectronics. Advanced Materials, 2019, DOI: 10.1002/adma.201904752.

[40] LING H, LIU L, LEE P S, et al. Layer-by-layer assembly of PEDOT:PSS and $\mathrm{WO}_{3}$ nanoparticles: enhanced electrochromic coloration efficiency and mechanism studies by scanning electrochemical microscopy. Electrochimica Acta, 2015, 174: 57-65.

[41] QU H Y, ZHANG X, ZHANG H C, et al. Highly robust and flexible $\mathrm{WO}_{3} .2 \mathrm{H}_{2} \mathrm{O} / \mathrm{PEDOT}$ films for improved electrochromic performance in near-infrared region. Solar Energy Materials and Solar Cells, 2017, 163: 23-30.

[42] LIU S P, WANG W. Improved electrochromic performances of $\mathrm{WO}_{3}$-based thin films via addition of CNTs. Journal of Sol-Gel Science and Technology, 2016, 80(2): 480-486.

[43] LI Q, LI K R, FAN H W, et al. Reduced graphene oxide functionalized stretchable and multicolor electrothermal chromatic fibers. Journal of Materials Chemistry C, 2017, 5(44): 11448-11453.

[44] SINGH R, THARION J, MURUGAN S, et al. ITO-free solutionprocessed flexible electrochromic devices based on PEDOT:PSS as transparent conducting electrode. ACS Applied Materials \& Interfaces, 2017, 9(23): 19427-19435.

[45] WEN H L, ZHI F, YANG Q B, et al. Enhanced electrochromic properties by using a $\mathrm{CeO}_{2}$ modified $\mathrm{TiO}_{2}$ nanotube array transparent counter electrode. Journal of Inorganic Materials, 2012, 27(1): 74-78

[46] GHICOV A, TSUCHIYA H, HAHN R, et al. $\mathrm{TiO}_{2}$ nanotubes: $\mathrm{H}^{+}$ insertion and strong electrochromic effects. Electrochemistry Communications, 2006, 8(4): 528-532.

[47] WANG J M, KHOO E, LEE P S, et al. Controlled synthesis of $\mathrm{WO}_{3}$ nanorods and their electrochromic properties in $\mathrm{H}_{2} \mathrm{SO}_{4}$ elec- trolyte. Journal of Physical Chemistry C, 2009, 113(22): 9655-9658.

[48] TONG Z, LIU S, LI X, et al. Achieving rapid Li-ion insertion kinetics in $\mathrm{TiO}_{2}$ mesoporous nanotube arrays for bifunctional high-rate energy storage smart windows. Nanoscale, 2018, 10(7): 3254-3261.

[49] PATEL K J, PANCHAL C J, DESAI M S, et al. An investigation of the insertion of the cations $\mathrm{H}^{+}, \mathrm{Na}^{+}, \mathrm{K}^{+}$on the electrochromic properties of the thermally evaporated $\mathrm{WO}_{3}$ thin films grown at different substrate temperatures. Materials Chemistry and Physics, 2010, 124(1): 884-890.

[50] SIAN T S, REDDY G B. Effect of adsorbed water vapor on $\mathrm{Mg}$ intercalation in electrochromic $a-\mathrm{MoO}_{3}$ films. Electrochimica Acta, 2004, 49(28): 5223-5226.

[51] LI K R, SHAO Y L, LIU S Y, et al. Aluminum-ion-intercalation supercapacitors with ultrahigh areal capacitance and highly enhanced cycling stability: power supply for flexible electrochromic devices. Small, 2017, 13(19): 1700380.

[52] DONG D M, WANG W W, ROUGIER A, et al. Life-cycling and uncovering cation-trapping evidence of a monolithic inorganic electrochromic device: glass $/ \mathrm{ITO} / \mathrm{WO}_{3} / \mathrm{LiTaO}_{3} / \mathrm{NiO} / \mathrm{ITO}$. Nanoscale, 2018, 10(35): 16521-16530.

[53] LIU Q R, DONG G B, CHEN Q Q, et al. Charge-transfer kinetics and cyclic properties of inorganic all-solid-state electrochromic device with remarkably improved optical memory. Solar Energy Materials and Solar Cells, 2018, 174: 545-553.

[54] TIAN Y Y, ZHANG W K, CONG S, et al. Unconventional aluminum ion intercalation/deintercalation for fast switching and highly stable electrochromism. Advanced Functional Materials, 2015, 25(36): 5833-5839.

[55] CHEN Y, XU Z, SUN J L. Present situation and future industrialization of large area intelligent electrochromic glass. Functional Materials, 2013, 44(17): 2441-2446.

[56] PENG M D, ZHANG Y Z, SONG L X, et al. Structure and electrochromic properties of titanium-doped $\mathrm{WO}_{3}$ thin film by sputtering. Journal of Inorganic Materials, 2017, 32(3): 287-292.

[57] CAI G F, TU J P, ZHOU D, et al. Dual electrochromic film based on $\mathrm{WO}_{3} /$ polyaniline core/shell nanowire array. Solar Energy Materials and Solar Cells 2014, 122: 51-58.

[58] WEN R T, GRANQVIST C G, NIKLASSON G A. Eliminating degradation and uncovering ion-trapping dynamics in electrochromic $\mathrm{WO}_{3}$ thin films. Nature Materials, 2015, 14(10): 996.

[59] BOGATI S, BASNET R, GEORG A. Iridium oxide catalyst for hybrid electrochromic device based on tetramethylthiourea (TMTU) redox electrolyte. Solar Energy Materials and Solar Cells, 2019, 189: 206-213.

[60] YOSHINO T, BABA N, ARAI K. Preparation of electrochromic irox thin film of periodic reverse electrolysis of sulfatoiridium complex solution. Journal of the Electrochemical Society, 1987, 134(8B): 440 .

[61] CAI G F, WANG X, CUI M Q, et al. Electrochromo-supercapacitor based on direct growth of $\mathrm{NiO}$ nanoparticles. Nano Energy, 2015, 12: $258-267$.

[62] LIU X X, ZHOU A, DOU Y B, et al. Ultrafast switching of an electrochromic device based on layered double hydroxide/Prussian blue multilayered films. Nanoscale, 2015, 7(40): 17088-17095.

[63] CHEN Y B, BI Z J, LI X M, et al. High-coloration efficiency electrochromic device based on novel porous $\mathrm{TiO}_{2} @$ Prussian blue core-shell nanostructures. Electrochimica Acta, 2017, 224: 534-540.

[64] HU C W, KAWAMOTO T, TANAKA H, et al. Water processable Prussian blue-polyaniline: polystyrene sulfonate nanocomposite (PB-PANI:PSS) for multi-color electrochromic applications. Journal of Materials Chemistry C, 2016, 4(43): 10293-10300.

[65] LI F, MA D Y, QIAN J H, et al. One-step hydrothermal growth and electrochromic properties of highly stable Prussian green film and device. Solar Energy Materials and Solar Cells, 2019, 192: 103-108.

[66] QIAN J H, MA D Y, XU Z P, et al. Electrochromic properties of hydrothermally grown Prussian blue film and device. Solar Energy Materials and Solar Cells, 2018, 177: 9-14. 